\title{
Silkworm and spider silk electrospinning: a review
}

\author{
Clémence Belbéoch ${ }^{1} \cdot$ Joseph Lejeune ${ }^{1}\left[\right.$ (D Philippe $\operatorname{Vroman}^{1} \cdot$ Fabien Salaün ${ }^{1}$
}

Received: 7 October 2020 / Accepted: 18 November 2020 / Published online: 4 January 2021

(c) Springer Nature Switzerland AG 2021

\begin{abstract}
Issues of fossil fuel and plastic pollution are shifting public demand toward biopolymer-based textiles. For instance, silk, which has been traditionally used during at least 5 milleniums in China, is re-emerging in research and industry with the development of high-tech spinning methods. Various arthropods, e.g. insects and arachnids, produce silky proteinic fiber of unique properties such as resistance, elasticity, stickiness and toughness, that show huge potential for biomaterial applications. Compared to synthetic analogs, silk presents advantages of low density, degradability and versatility. Electrospinning allows the creation of nonwoven mats whose pore size and structure show unprecedented characteristics at the nanometric scale, versus classical weaving methods or modern techniques such as melt blowing. Electrospinning has recently allowed to produce silk scaffolds, with applications in regenerative medicine, drug delivery, depollution and filtration. Here we review silk production by the spinning apparatus of the silkworm Bombyx mori and the spiders Aranea diadematus and Nephila Clavipes. We present the biotechnological procedures to get silk proteins, and the preparation of a spinning dope for electrospinning. We discuss silk's mechanical properties in mats obtained from pure polymer dope and multi-composites. This review highlights the similarity between two very different yarn spinning techniques: biological and electrospinning processes.
\end{abstract}

Keywords Electrospinning $\cdot$ Electrospinning mat $\cdot$ Spider web $\cdot$ Bombyx mori $\cdot$ Nephila clavipes $\cdot$ Aranea diadematus $\cdot$ Biomimetic · Silk · Bombyx mori's silk · Spider's silk · Bio polymer · Polymer · Regenerated silk · Mechanical properties · Tensile test $\cdot$ Sustainability $\cdot$ Life cycle $\cdot$ Degradability $\cdot$ Supercontraction

\section{Introduction}

Textile industry is one of the most demanding industry in water (Varadarajan and Venkatachalam 2016). But wastewater is not the only waste occurring from textile industry, indeed microplastics originating from the textile industries are pointed out as a major problem (Herbort et al. 2018; Padervand et al. 2020). Recent development due to COVID-19 disease, further increased this problematic. Indeed the usage of protection mask and gloves, strongly reduce the numerous effort that several country were engaged in to reduce the usage of throwaway plastics (Gorrasi et al. 2020). In this context, why not coming back to the origin of textile and the usage of bio-sourced and therefore bio degradable material.

Joseph Lejeune

joseph.lejeune@ensait.fr

1 ENSAIT: Ecole Nationale Superieure des Arts et Industries Textiles, Roubaix, France
Especially since given proper preparation these materials are sometimes able to compete with synthetic polymers.

For millennia, arthropod (arachnids, insects and myriapods) silk has been known to humans as an exceptional biomaterial. First mentions of silkworms domestication are dated to more than 5000 years before our era, originating from Chinese regions (Yu et al. 2011; Babu 2018). After hatching from its egg, the silkworm, still under its larvae shape, produces a cocoon to protect itself during its transformation in a moth. If a variety of silkworms are found in nature, most producing these silky structures, the main species which was domesticated and raised in industrial farms is the Bombyx mori (Guo et al. 2011), because of the finest silks that it produces for textile applications. The material is still used today for its qualities, such as strength, luster, drapability, resilience and ability to bind with chemical dyes. But it has also been recognized for its applications in medicine. The silk market represents a huge part of the worldwide textile economy, with 120000 tons of silk produced every year, mainly in Asia (Pereira et al. 2015). Throughout 
history silkworm's threads have been used to sew wounds. From its superior mechanical resistance (stronger than collagen) (Thilagavathi and Viju 2015), and its biocompatibility once ridden of their sericin coating (Vepari and Kaplan 2007), several applications arose. If silk from Bombyx mori has been deeply studied thanks to its availability from to sericulture, silks from other arthropods, such as spiders, have for a long time remained confined to research. Arachnid species cannot be raised in farms because of their cannibal tendencies, but their silk, with its very specific features that combine strength and elasticity, has been in the past used as fishing lines (Vierra et al. 2011) and more recently as microsutures (Kuhbier et al. 2011). The recent research infatuation with spider silk, or more accurately spider silks as the fiber declines in 7 types all with specific uses, resides in its diversity. Consequently, its potential is largely unexplored due to its scarcity. This fact made it a luxury product in our collective imagination: in 2012, artist Simon Peers and entrepreneur Nicholas Godley created a naturally golden cape made out of the silk of 1.2 million Nephila spiders, that was exposed in London (Chung et al. 2012).

Traditionally, silk was spun by hand. After degumming the fibers, they were dried and stretched in caps and hankies, before being woven using a spinning wheel. Average productions with these methods rose to $200 \mathrm{~g}$ of spun silk per day and per spinner (Chakravorty et al. 2010). In these conditions, the obtained fibers are vowed to be worked into a fabric and are therefore about half a millimeter in diameter, a common size for yarns in clothing manufacture. The final silk piece textile is a woven mat, with organized and structured fibers crossing and interlacing (Cao et al. 2008). This type of material has advantages, for its mechanical properties and structural resilience to shearing, but its applications are confined to clothing. In 1934, Formhals invented a new way to spin fibers, named electrospinning (Bognitzki et al. 2001). An electric field applied to a solution of dissolved polymer generates the sufficient tension to create a stream jet from a syringe to a collector, randomly splashing spun fibers as they dry into a nonwoven mat. The obtained fabric possesses, among other unique properties, fibers' diameters ranging from a micrometer to a few nanometers (Ramakrishna 2005). Electrospun fibers of silkworm's threads have given nonwoven mats which combined the interests of the nanometric scale, such as high specific surface and the inherent properties of the silk, like biocompatibility, durability, strength, elasticity or a particular ability to drape (Babu 2018). Nevertheless, silkworm's silk remains a soft polymer, that cannot compete with the synthetic fibers like aramids or polyamides when it comes to strength, or elastane for elasticity (Senthilkumar et al. 2011). This is where spider silk has the advantage. Numerous studies show the spider silk's amazing potential in terms of mechanical possibilities. Not only does it offer a high resistance under tension and some significant elastic properties, but most importantly a versatility in these two parameters that is not met in any other polymer. It is also more durable than Bombyx's silk because degrading slowly (Vierra et al. 2011), resistant to extreme temperatures (Babu 2018), with piezoelectric properties (Fukada 1956) and biocompatible because naturally clear from sericin proteins (Karthik and Rathinamoorthy 2017). Thanks to the diversity of uses that a spider makes of its silk, from catching preys to wrapping egg sacs, exist a variety of silks based on different proteins and with different features (Vierra et al. 2011).

Nowadays, as engineering world tends to use a life friendly and sustainable designing approach, the development of biomaterials and respectful alternatives to synthetic polymers has become trendy. Numerous ecologically involved organizations recommend the integration of biomimicry principles in the concepts creation (Benyus 1997; Reap et al. 2005). This implies that the inspiration to design new components could arise from Nature. Indeed, Nature has the sufficient experimental background, provided by evolution, to create optimal components. This review aims to integrate these concepts, as silk is an ancient and perfected polymer with well-studied specific applications in ecology. The applications of its properties of interest for human technologies seem like a responsible bet. The utilization of a natural material guarantees the relative safety of manipulation, since Life does not build with blocks that could not, eventually, be naturally broken down by other organisms (Green chemistry) (Kirchhoff 2003). Morphologically, the spigots of a spider are similar to the industrial spinnerets used in textile spinning, electrospinning voltage energy providing the necessary tension to spin the fiber, as rear legs of a spider would do in nature (Das et al. 2015). Therefore, this work endorses a critical approach on experimental procedures and their footprint on the environment.

This review provides the necessary background on the biological models and original polymer producers, focusing mainly on the silkworm Bombyx mori and the few spider's species that are met in relevant literature, Aranea diadematus and Nephila clavipes. The diverse advantages of silk fibers in contextual comparison with other bio or artificial polymers is presented in a second time and a detailed selection of experimental procedures to obtain and electrospinning of these fibers follows. Characterization and applications for electrospun silk mats in various domains, such as regenerative medicine, drug delivery, structural support, filtration, depollution and textiles are also discussed.

\section{Arthropods and silk}

\section{Origin of silk in animal phylae}

Silk, according to the different contexts it is used in, has many definitions. Back to its most universal, and natural 
approach, it is defined as a structural protein fiber synthetized by an organism for an external use (Holland et al. 2019). It is produced by a variety of animals in nature, all part of the phylum of arthropods. All organisms producing silk originally benefited from the same genetic innovation, as the ancestral gene appeared about 400 million years ago (Chen et al. 2006) and diversifying ever since. This led to the variety of silk structures and properties observed nowadays. Modern species producing silk include silkworms, from the Insecta class, spiders and pseudoscorpions, from the Arachnida class and other species from the Myriapoda class (Craig 1997). Ecologically, the silk has diverse applications, depending on the considered taxon. The chemical structure of the silk depends on its final purpose, in a form-to-function relationship (Tokareva et al. 2014). Hence, different types of silk are observed within the different species, different individuals and different contexts. Silk therefore displays a range of mechanical properties, from adhesion to high strength, or elasticity. Nonetheless, in all organisms producing this biomaterial, the proteins are synthetized in the silk glands organs, whose walls are made of epithelial cells that release of the proto silk in the lumen under its liquid form. The polymer is then stretched, being spun out of the body through the spinnerets or spigots (Altman et al. 2003) (Fig. 1). These glands, originally derived from the digestive tract and secreting primitive fibrous compounds, are located at different positions depending on the type of animal (Craig 1997).

\section{Fibroin, sericin and other components of silk}

Several molecular families of silk proteins exist in arthropods. Fibroin, present in all silks, is the core protein of the fiber. It is composed of amino acids disposed in beta-sheets (crystalline domains linked by disulfuric bonds). Two-thirds of the protein are crystalline, the rest is amorphous, allowing the creation of hydrogen bonds between the amino acids (Wade 2015). The heavy chain of the protein is an alternance of hydrophobic and hydrophilic domains, based on the nature of their amino acids. This alternance creates physicochemical interactions between the domains. That confers the resistance to the final polymer. The side chains of the protein are hydrophobic. Fibroin is observed in all arthropod silks, for it represents the essential structure of the thread and confers its strength. Another silk component, sericin is a hydrophilic protein coating the fibroin core, which provides adhesion, stickiness and hydration to the silk in silkworm species (Vepari and Kaplan 2007). Sericin is constituted of side chains, of five different structures, that can bind to the fibroin heavy chains via their carboxyl, hydroxyl and amino groups (Numata and Kaplan 2010). Resistance of the silk as a biomaterial originates from the elastic deformation of the beta-sheets under traction, the disulfuric bonds keeping the chain strong, while amorphous chains' hydrogen bonds are untied and reformed after the deformation (Liu et al. 2017). In spiders, the fibroin core is not coated with sericin, but with a three-layers covering. The first layer is a skin wrapping the nanofibrils of fibroin, topped by glycoproteins and
Fig. 1 Physiology of a Bombyx mori's (left) and an Aranea diadematus' (right) spinning apparatus. The silkworm uses its unique buccal spinneret to spin a single thread for its cocoon. The spider possesses five individual spinnerets and uses its rear limbs to spin the thread out of them. Each contains numerous microtubules (middle) that synthesize the nanofibrils of fibroin. Silkworms do not possess microtubules

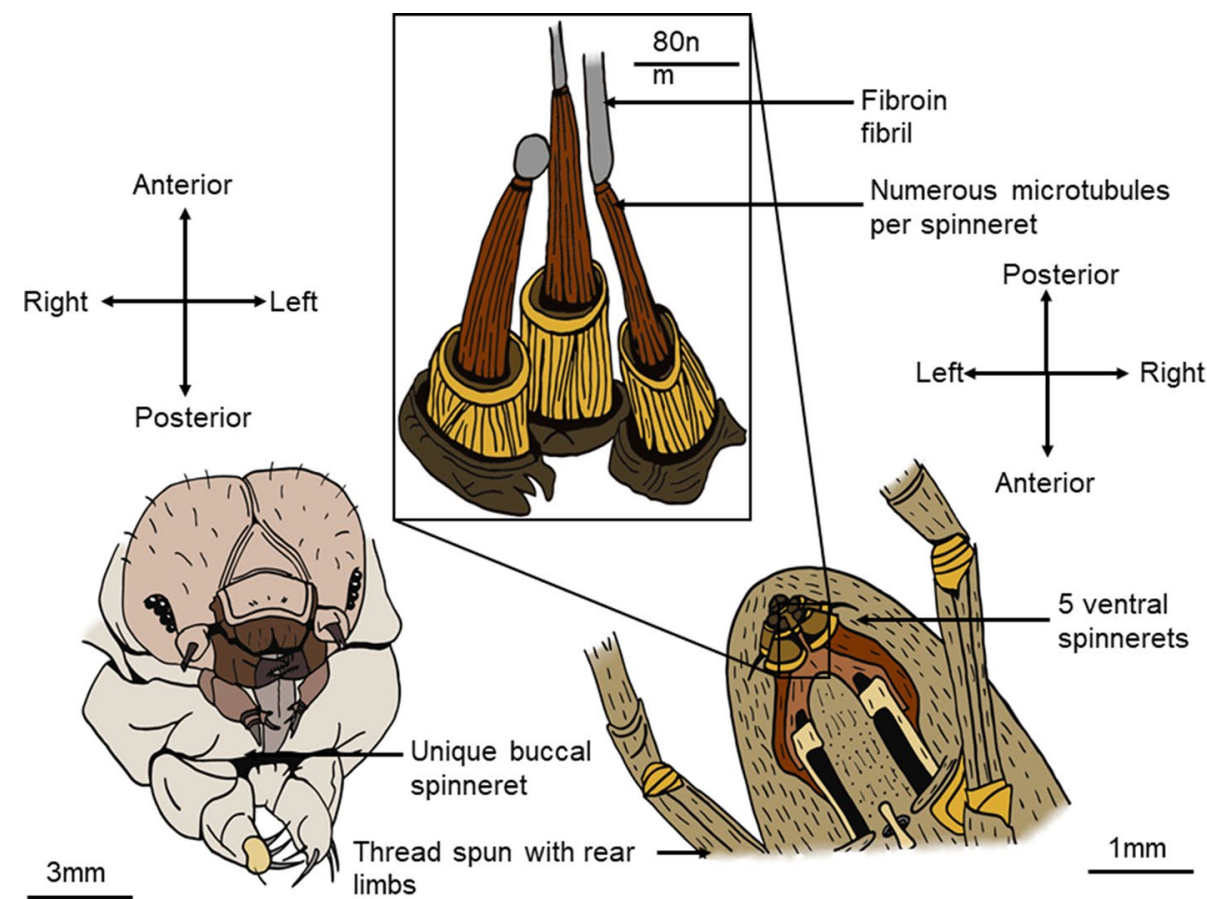


a final sheet of lipids. This assemblage provides the silk its antibacterial and antifungal properties (Romer et al. 2008).

\section{Bombyx mori's silk}

The most famous and common silk encountered in literature is the silk of Bombyx mori. Its commonness is due to its ancient utilization in textile (Merrit et al. 1992) and numerous industrial applications. Bombyx mori is a silkworm that turns into a moth in its adult phase. This animal has been domesticated for several thousands of years for its silk, which is the raw material used for common textile silk (Merrit et al. 1992). The Lepidoptera, still under its larvae shape, spin a single long silk thread (up to $20 \mu \mathrm{m}$ of diameter) with adhesion and resistance properties to create its pupa: the protective cocoon in which the larvae will be transformed into an adult (Chen et al. 2012). The silk proteins are issued from what were formerly salivary (labial) glands, that have been modified throughout evolution into silk glands (Suzuki et al. 1972). These silk glands (one bilateral pair) extend through the whole body of the insect: the posterior part produces the fibroin core, and the middle part synthetizes the sericin. The sericin is a coating around the naked fiber. The anterior part, tighter, acts as a lumen, that will elongate the proteins and shape them into their final solid state (Laity and Gilks 2015; Takai et al. 2018). At last, the single thread is spun from the unique buccal spinneret and will constitute the cocoon (Fig. 1). This thread is composed of two central clusters of numerous fibroin nanofibrils (of $20 \mathrm{~nm}$ each), coated with sericin (Fig. 2). The silk of Bombyx's properties (Table 1) depends on the speed of spinning. A thread spun fast $(27 \mathrm{~mm} / \mathrm{s})$ is more resistant to the rupture than a thread spun slowly $(4 \mathrm{~mm} / \mathrm{s})$ which is more elastic. These two characteristics in the silkworm's silk can therefore not be combined in a same fiber, the thread is either strong or extensible (Shao and Vollrath 2002). A few other silkworms, like Antheraea or Samia, also produce silks. These fibers are known as non-mulberry silk: they share a lot of similarities, their difference lying mainly in the luster of the obtained fabric.

\section{Spider's silk}

The Arachnida class also produces silk, sharing a common ancestor with Bombyx, living 240 million years ago (according to the silk genes analysis) (Garb et al. 2010; Blackledge et al. 2012). 37,000 species of spiders produce silk, and, unlike silkworms, their silk is designed in several declinations depending on their final utilization. Indeed, spiders such as Aranea diadematus, or Nephila clavipes, two wellstudied model species, possess not one but seven types of silk glands in their posterior abdomen. Each is responsible for the synthesis of a specific silk compound, with diverse

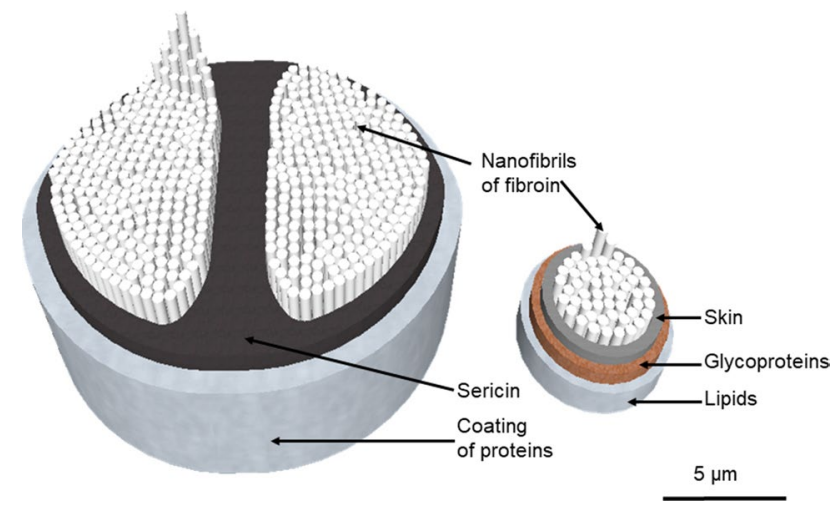

Fig. 2 Tridimensional structures of Bombyx mori's silk fiber (left) and Aranea diadematus's (right). The silkworm's fiber varies between 10 and $20 \mu \mathrm{m}$, the spider's dragline between 3 and $5 \mu \mathrm{m}$. Unlike in silkworm's silk, there is no sericin in spiders' dragline, but the glycoproteins layer protects from bacterial and fungal infections (Doblhofer et al. 2015). Nanofibrils of fibroin (in spiders and silkworms indifferently), which are between 20 and $60 \mathrm{~nm}$ large, are not represented at scale

chemical compositions and structures (Tokareva et al. 2014). The synthesis of silk in these glands is a complex process. In the fore part of the gland, the tail, the columnar epithelial cells secrete the proteins of spider fibroin (spidroin). The proteins gather in small micelles, which avoid their aggregation before spinning because of high glandular concentrations. The micelles then migrate to the lumen, or duct, a tight $\mathrm{S}$-shaped corridor in which they are elongated. The proteins are gradually organized into crystalline beta-sheets regions and amorphous chains. All along this path, the formation of the crystal sheets is facilitated by ions exchanges, and water is recapture. The elongation forces applied on the proteins also induce the solidification of the fiber, which is ready to be spun at the end of the duct (Eisoldt et al. 2011; Tokareva et al. 2014). In the late stages of the polymer synthesis, the microfibers are secreted outside of the body by external microtubules (Fig. 1) present in the spinneret. Fibroinsecreting microtubules are numerous and about $20 \mathrm{~nm}$ in diameter and synthetize the core of the fiber. This core of microfibers is then coated by the glycoproteins and lipids (Fig. 2) (Romer et al. 2008; Nentwig 2012). The whole fiber then emerges from the spinneret and is pulled out by the rear legs of the spider (He et al. 2008). Properties of spider threads are mentioned in Table 2.

The seven glands of the spider do not serve the same purpose (Fig. 3) (Vierra et al. 2011). The ampullate major produces the dragline of the spider and some structural threads for the web, this last being also achieved by ampullate minor for radial strings. The aciniform gland synthetizes silk for prey wrapping, the cylindriform (or tubuliform) for eggs sac wrapping and the pyriform for joints (Vollrath and Knight 2001). While building its web, the spider will pass a first 
Table 1 Characteristics of the silk thread of silkworm Bombyx mori. Composition and molecular structure of the cocoon silk, and mechanical properties under tension. See references for experimental protocols

\begin{tabular}{|c|c|c|c|}
\hline \multirow{2}{*}{$\frac{\text { Characteristic of the silk }}{\text { Molecular weight }(\mathrm{kDa})}$} & \multicolumn{2}{|l|}{ Type of silk } & \multirow{2}{*}{$\frac{\text { References }}{\text { Garb et al. (2010) }}$} \\
\hline & Fibroin & 360 (heavy chain) & \\
\hline & & 25 (light chain) & \\
\hline & Sericin (five polypeptide types) & From 80 to 309 & Garb et al. (2010) \\
\hline \multirow[t]{2}{*}{ Composition in main amino acids } & Fibroin & Alanine, glycine, serine, tyrosine & Altman et al. (2003) \\
\hline & Sericin & $\begin{array}{l}\text { Serine, glycine, glutamic acid, } \\
\text { aspartic acid, threonine, } \\
\text { tyrosine }\end{array}$ & Numata and Kaplan (2010) \\
\hline \multirow[t]{2}{*}{ Structure of the natural fiber } & Core of fibrils' structure & Bipartite & Du et al. (2011) \\
\hline & Thread diameter & 10 to $20 \mu \mathrm{m}$ & Du et al. (2011) \\
\hline \multirow{2}{*}{$\begin{array}{l}\text { Ultimate tensile strength of the } \\
\text { silk fiber }(\mathrm{MPa})\end{array}$} & Natural fiber & 500 & Pérez-Rigueiro et al. (2000) \\
\hline & Degummed (without sericin) & 240 to 700 & (Zhao et al. 2006) \\
\hline \multirow[t]{2}{*}{ Strain at break $(\%)$} & Natural fiber & 15 to 19 & $\begin{array}{l}\text { Pérez-Rigueiro et al. (2000); Zhao et al. } \\
\text { (2006) }\end{array}$ \\
\hline & Degummed (without sericin) & 4 to 16 & (Pérez-Rigueiro et al. 2000) \\
\hline Stiffness (GPa) & Natural fiber & 7 & $\begin{array}{l}\text { Shao and Vollrath (2002); Heim et al. } \\
\text { (2009) }\end{array}$ \\
\hline Toughness $\left(\mathrm{MJ} . \mathrm{m}^{-3}\right)$ & Natural fiber & 70 & $\begin{array}{l}\text { Shao and Vollrath (2002); Heim et al. } \\
\text { (2009) }\end{array}$ \\
\hline Density $\left(\mathrm{g} \cdot \mathrm{cm}^{-3}\right)$ & Natural fiber & 1.3 & Romer et al. (2008) \\
\hline
\end{tabular}

Table 2 Characteristics of the dragline silk produced by the ampullate major gland, and of the spiral thread silk produced by the flagelliform gland in the spider Aranea diadematus. Composition and struc-

\begin{tabular}{|c|c|c|c|}
\hline \multirow{2}{*}{$\frac{\text { Characteristic of the silk }}{\text { Molecular weight }(\mathrm{kDa})}$} & \multicolumn{2}{|l|}{ Silk type } & \multirow{2}{*}{$\begin{array}{l}\text { References } \\
\text { Ayoub et al. (2007) }\end{array}$} \\
\hline & Fibroin (spidroin) & Up to 350 & \\
\hline Composition in main amino acids & Dragline & $\begin{array}{l}\text { Glycerin, alanine, proline, } \\
\text { glutamic acid, serine }\end{array}$ & Andersen (1970) \\
\hline \multirow[t]{2}{*}{ Structure of the fiber } & Core of fibril's structure & Simple & Du et al. (2011) \\
\hline & Thread diameter & 3 to $5 \mu \mathrm{m}$ & Du et al. (2011) \\
\hline \multirow{2}{*}{$\begin{array}{l}\text { Ultimate tensile strength of the silk } \\
\text { fiber }(\mathrm{GPa})\end{array}$} & Dragline & 1.1 to 1.2 & Pérez-Rigueiro et al. (2000); Du et al. (2011) \\
\hline & Spiral thread & 0,3 & (Pérez-Rigueiro et al (2000).; Du et al. 2011) \\
\hline \multirow[t]{2}{*}{ Strain at break $(\%)$} & Dragline & 20 to 27 & Pérez-Rigueiro et al. (2000); Du et al. (2011) \\
\hline & Spiral thread & 270 & Pérez-Rigueiro et al. (2000); Du et al. (2011) \\
\hline \multirow[t]{2}{*}{ Stiffness (GPa) } & Dragline & 10 & Pérez-Rigueiro et al. (2000); Du et al. (2011) \\
\hline & Spiral thread & 0.003 & Pérez-Rigueiro et al. (2000); Du et al. (2011) \\
\hline \multirow[t]{2}{*}{ Toughness $\left(\mathrm{MJ} \cdot \mathrm{m}^{-3}\right)$} & Dragline & 180 & Pérez-Rigueiro et al. (2000); Du et al. (2011) \\
\hline & Spiral thread & 150 & Pérez-Rigueiro et al. (2000); Du et al. (2011) \\
\hline \multirow[t]{2}{*}{ Density $\left(\mathrm{g} \cdot \mathrm{cm}^{-3}\right)$} & Dragline & 1.3 & Romer et al. (2008) \\
\hline & Spiral thread & 1.3 & Romer et al. (2008) \\
\hline
\end{tabular}

ture of the silk threads and mechanical properties under tension. See references for experimental protocols time to design the spiral that will catch the preys, secreting a core silk from the flagelliform gland and then a second time, to coat this core with sticky glycoproteins and lipids issued from the aggregate glands (Liu and Zhang 2014). These different silk compounds, whom synthesis is ruled by different genes (Craig and Riekel 2002), have different properties once secreted, the dragline and structural threads being the most resistant and stiff ones, whereas the spiral fibers will be the most elastic and sticky (Shear et al. 1989).

Unlike silkworm silk, spider silk can achieve supercontraction: the fiber contracts above a humidity threshold. This phenomenon, associated with an increase in the ambient 
Fig. 3 Highlighted types of spider silk in webs and cocoons (various species). Major ampullate gland silk in frame and radial threads (a), minor ampullate gland silk in spiral thread (b), flagelliform gland silk in capture thread (c), pyriform gland silk in attachments (d), aciniform gland silk in prey wrapping (e), and cylindriform gland silk in eggsack (f). Aggregate gland silk, which coats the spiral thread, is not represented. Figure inspired by Eisoldt et al.'s work (Eisoldt et al. 2011). Photographs free from rights.

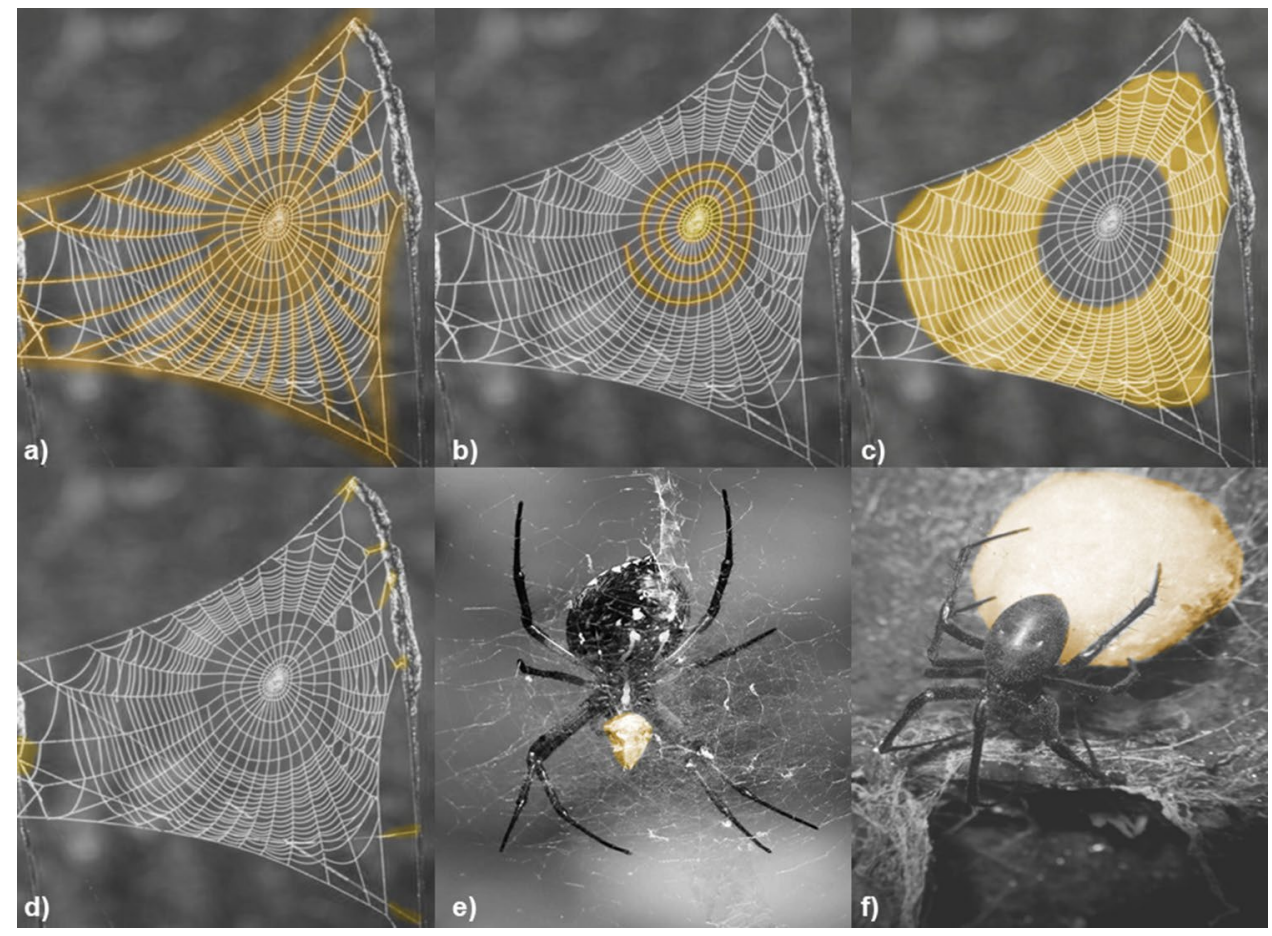

humidity, generates a contraction strength up to $22 \%$ of the energy necessary to break the thread (studies realized in dragline from Nephila clavipes) (Bell et al. 2002). The fiber shrinks when wet, up to $50 \%$ of its original length, and then returns to normal after $5 \mathrm{~min}$ in the experimental conditions. Interestingly, the silk does not only response to humidity with supercontraction. Studies also show a cyclic contraction-relaxation of the fiber under the effect of humidity and dryness, respectively. Post supercontraction threads have a slightly higher weight and a lower stiffness (Blackledge et al. 2009). Biological purpose of such phenomenon is uncertain, but it may contribute to the resilience of the thread and avoid sagging (Boutry and Blackledge 2010). Additionally, and whereas supercontraction is considered as a chemical property of the biomaterial, silk threads' tension can be modulated by liquid droplets known as elastocapillary winches. The thread can wind around the water drop, and unwind to will to damp the kinetic energy developed when stopping a flying insect, like a yo-yo, adding to the elongation potential of the web (Neukirch et al. 2017 [CSL STYLE ERROR: reference with no printed form.]).

\section{Silkworm and spider silk: mechanical comparison and proteinic origin}

Differences between silkworm and spider's silk are previously mentioned in this review (Tables 1,2). A.diadematus model spider dragline's diameter is three times smaller than the cocoon thread of B.mori. Their structure also differs, in the organization of the nanofibril clusters (Fig. 2). Most importantly, the mechanical properties of the fibers, silkworm's thread, spider's dragline and spider's spiral thread, are highly variable. The silkworm synthetizes a thread to wrap itself in its cocoon, aiming for an insulating, protective material. The obtained fiber hence does not show an ultimate tensile strength, elasticity, stiffness or toughness as high as in spider's dragline, whose purpose is to suspend the web or the spider (Vollrath and Knight 2001). Interestingly, the spiral thread from the spider shows an extreme elasticity, in order to catch the flying preys (Fig. 4). Nevertheless, only the combined properties of resistance (of the dragline made by the ampulla major) and the stretchiness of the spiral thread can absorb the kinetic energy of a jumping or flying insect (Casas 2011).

Despite sharing the same density of $1.3 \mathrm{~g} \mathrm{~cm}^{-3}$ (categorized as low density polymer (Blackledge et al. 2009)), silkworm's and spider's silks have different composition. The nature of the amino acids present in the fiber's molecular structure confers the mechanical properties to the fiber, whether it is elastic or resistant. This phenomenon is even more pronounced in spider silks.

Figure 5 shows the correlation coefficient between a given amino acid and mechanical resistance or elasticity of a spider thread. A positive coefficient suggests an increase of the properties with the presence of the amino acid whereas a negative coefficient means a decrease. Finally, a coefficient close to zero implies a lack of influence of the presence of the amino acids. The dragline is mainly based on glycine, alanine, proline and glutamic acid (Andersen 1970): glycine and alanine have a strong influence on mechanical 
Fig. 4 Bombyx mori and Aranea diadematus' silks properties: ultimate tensile strength (a), strain at break (b), Stiffness (c) and Toughness (d). Dragline silk is the stiffest, toughest and the most resistant fiber, while spiral thread is significantly more elastic than any other compared fibers. For these advantages, spider threads are also thinner than silkworm's one. Graphs made from references (Pérez-Rigueiro et al. 2000; Shao and Vollrath 2002; Bonino 2003; Heim et al. 2009)
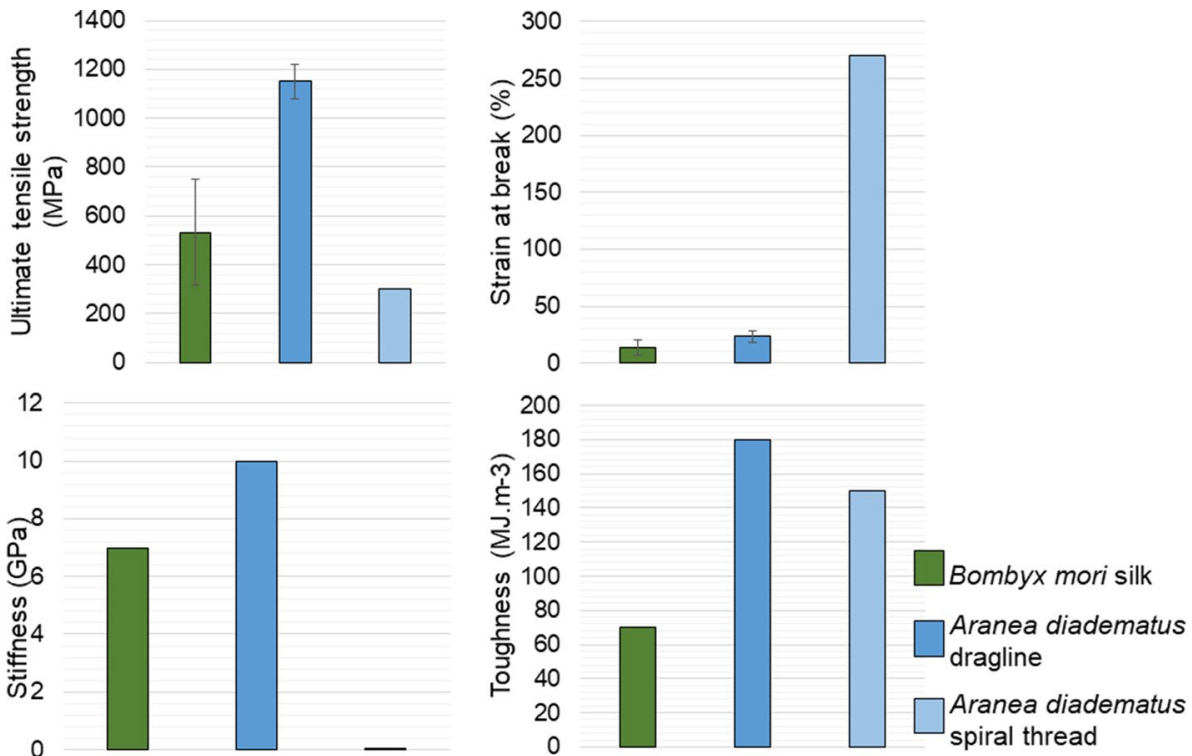

resistance's augmentation. The spiral thread is composed of glycine, proline and valine only (Andersen 1970): proline and valine increase the elasticity of the fiber. The adhesive coating that covers the flagelliform thread to catch insects is mostly made of glycine and proline (Andersen 1970). If the presence of single amino acids plays a role in the properties of the fiber, it is mainly their assemblage in clusters that provide the final mechanical profile of the fiber (Vollrath and Knight 2001).

\section{Performance of silks versus other materials}

Silks are unique as biopolymers. They range among the rare fibers from animal origin that are used in a context similar to human activities, centered around the shape of a thread. Indeed, whereas most fibers originating from living organisms are used for structure (cellulosic fibers, collagen, elastin) or protection (keratin from wool and hairs), silks and mainly spider silks, are designed to be single strings with

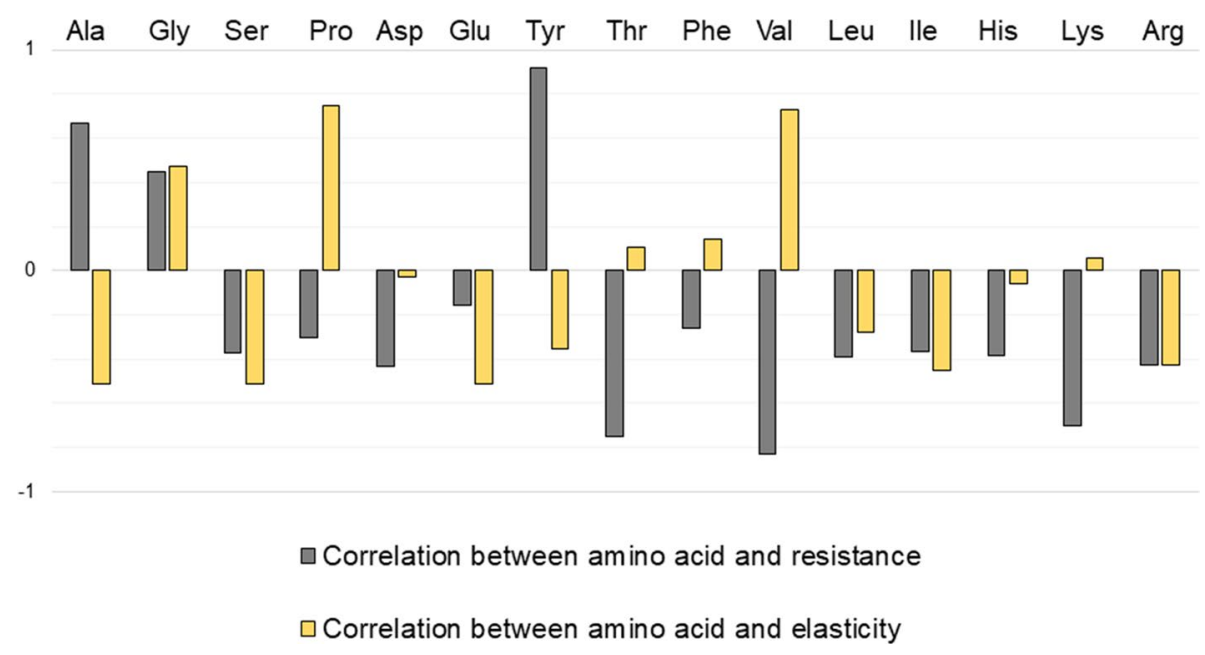

Fig. 5 Correlation test of Pearson between amino acid composition and mechanical properties (mechanical resistance and elasticity) of spider silks (A.diadematus and N.clavipes). A correlation test was performed between the composition in amino acids of silk issued from aciniform, cylindriform, flagelliform, ampullate major and ampullate minor glands (Andersen 1970), and the ultimate tensile strength or strain at break for these different silks (Vollrath and Porter 2006). A positive value indicates a correlation between the propor- tion of the amino acid and the mechanical property, a negative value suggests a correlation between the proportion of the amino acid and the other property (deleterious effect of the amino acid on the considered mechanical characteristic). Legends for the amino acids in order of mention: alanine, glycine, serine, proline, aspartic acid, glutamic acid, tyrosine, threonine, phenylalanine, valine, leucine, isoleucine, histidine, lysine, arginine 
the consequent behavior. Hence, their pristine mechanical properties can be compared with natural and artificial synthetic homologues.

\section{Biopolymer's advantages}

\section{Evolution, selection and form-to-function relationship}

As previously mentioned, unlike modern materials, silk is not a synthetic product. The fiber appeared in the arthropod phylum about 400 million years ago (Craig and Brunetta 2010) as a primitive secretion. The silk in the Araneae family (or in primitive Araneomorphae) started to gain its specific features, such as supercontraction, around 200 million years ago (Boutry and Blackledge 2010). The divergence of the types of silk, namely in the spiders' family, is due to the motor of evolution: genetic lottery conferred the spun silk a variety of molecular structures that are adaptative. Not only the final structure is fit to a defined use, such as wrapping, stopping insects or suspension, but the building blocks used for its synthesis can be modulated depending on what is available in the environment. The environment and context also play roles on the final fiber obtained, which adds to the potential of the biomaterial. Humidity, building blocks, speed, substrate and orientation of spinning are all parameters that control the mechanical behavior of the thread (Swanson et al. 2009). Even further, spiders are believed to be capable of tailoring their filaments by post-spinning adjustments (Eisoldt et al. 2011). The characterization and quantification of these features highlight the potential of a smart material in an identified context, an opportunity for engineering. In opposition with synthetic polymers that do not attempt to recreate the shape-to-function relationship of silk, this last is strong of millions of years of adaptations and experiences a significant modularity in its features.

\section{Sustainability, degradability and life cycle}

Silk is a natural polymer, its composition is basically amino acids, rich in nitrogen and carbon (Andersen 1970). If the degradability of silk is relatively low and the material is classified like resilient against degradation, as it starts to lose its initial properties after a period varying between 60 days and 2 years depending on the context (Altman et al. 2003). If worn silk is not recycled into a new product or if its lysis is necessary in some application, it is possible to degrade silk using organic processes, in a circular way. Some proteases, like chymotrypsin ( $\mathrm{Li}$ et al. 2003), can break down the fibroin core into smaller compounds whose reintegration in other building blocks will be done naturally like it is in nature. As silk is employed for regenerative medicine, its controllable and non-toxic degradation matters. MüllerHerrmann and Scheibel studied the degradation of spider silk by two bacterial proteases, with conclusive results for biomedical purposes (Müller-Herrmann and Scheibel 2015). Whether degradation is studied in order to break down cell scaffolds after tissue regeneration or to prove the biodegradability of silk for other applications, the biomaterial has the advantage of natural recyclability. In terms of green chemistry, silks, including spider silks, can replace a part of the petrol-based materials thanks to their properties, with a life cycle assessment proving its sustainability. During its synthesis process, silk is considered as an aquamelt, which means that it can be turned from a polymeric dope to a crystallized polymer in ambient temperature and water, whereas regular polymers need some heat input to do so. As so, the spinning of silk in artificial conditions saves up to $90 \%$ of the energy necessary for its shearing to reach fibrillation, last step before the final crystallization (Holland et al. 2012). A particular example is about domestic air filters made from spider silk instead of regular synthetic fibers, which could save $9 \mathrm{~kg}$ of $\mathrm{CO}_{2}$ per house and year (Lauterbach and Scheibel 2015).

\section{Silk obtention and preparation obstacles}

Industrial alternatives to plastics involving silks have been explored. However, the difficulty of its production, particularly for spidroins, do not allow the complete switch from synthetic material to biopolymer in the future; the applications remain extremely specific and too rare and expensive (raw material and production) for a broad use in our consuming lifestyle (Karthik and Rathinamoorthy 2017). Only a material mimicking the structure, the molecular interactions that result in the outstanding properties of silk could be competitive, not the natural material itself. Nevertheless, biotechnological alternatives for obtention of the silk proteins in higher quantities exist and have been thriving these last decades.

\section{Mechanical parameters of silk}

\section{Ultimate tensile strength: strong, but not the strongest}

Spider silk has arisen in literature as a strong, resistant fiber. Although this is true in the ecological context of the animal (webs can stop flying insects with high kinetic energy), silk is not the strongest fiber, outdone by artificial threads. Concerning Bombyx, as it has been previously described, its silk only possesses the advantage of adhesivity and ease of production (Karthik and Rathinamoorthy 2017), (Table 1); the material is not even ranking among high-strength fibers. Most of studies compare the spider thread issued from ampulla major, the dragline, with high resistance synthetic products such as Kevlar ${ }^{\circledR}$ (poly-paraphenylene terephthalamide), steel, Nylon (polycaprolactam or polyamide-6) 
(Altman et al. 2003). In this review, we should also compare it with other strong textile fibers like Zylon ${ }^{\circledR}$ (poly(pphenylene-2,6-benzobisoxazole)), Vectran ${ }^{\circledR}$ (polyarylate) or UHWPE (ultra-high molecular weight polyethylene). These selected materials are used for design of various high resistance gear, for clothing, fishing, sailing, chutes, cable reinforcement, or ballistics. Spidroin, the core of fibroin of the dragline's thread, is not as resistant as most of these filaments. Its maximal ultimate tensile strength rises up to $1.75 \mathrm{GPa}$ (for certain species and under certain conditions). Zylon ${ }^{\circledR}$ fibers endure a stress up to $5.8 \mathrm{GPa}$ (Zhang et al. 2018), Kevlar $^{\circledR}$ up to $3.62 \mathrm{GPa}$ (Quintanilla), Vectran ${ }^{\circledR}$ up to $3.3 \mathrm{GPa}$ (Ward 2012), UHMWPE fibers up to $2.8 \mathrm{GPa}$ (Ogawa et al.) and stainless steel fibers up to $2.21 \mathrm{GPa}$ (De Araújo 2011). However, spider silk remains more resistant than Nylon (polyamide 6), whose ultimate tensile strength rises up to $1.5 \mathrm{GPa}$ (Bhattacharyya et al. 2009). Spider silk is a natural long thread with the original purpose of stopping insects. Given this inherent objective, one could expect silk to be the strongest of all natural fibers; however, some cellulosic structures actually prevail. Flax is the strongest fiber (maximal UTS $=2 \mathrm{GPa}$ ), even stronger than spider silk. Our biomaterial comes second, followed by PALF fibers (maximal UTS $=1.63 \mathrm{GPa}$ ), curaua fibers $($ maximal UTS $=1.15$ ), ramie fibers (maximal UTS $=0.81 \mathrm{GPa}$ ) (Jamaluddin et al. 2019), cotton fibers (maximal UTS $=0.8 \mathrm{GPa}$ ) (Yan et al.), and wool fibers (maximal UTS $=0.17$ ) (Yükseloğlu et al. 2015).

\section{Strain at break: second place for a versatile fiber}

We demonstrated that silk, although being a strong fiber, does not surpass synthetic filaments. However, the interest of silk and mostly of spider silk, resides in its versatility (Fig. 6). Where other materials possess either one strong feature or another, it is possible for silk to have both a resistant and elastic (or plastic) behavior (Huang et al. 2018). This is a characteristic of biopolymers, that results of the chemical bonds between the chains and their structure (see Sect. 1.2): the very developed network of hydrogen bonds between amino acids in the relaxed thread and the covalent bonds between proteins in the nanocrystalline regions as a safety backup when stretched (Nova et al. 2010). The ratio between resistance and elasticity for silk and mostly spider silk, is unique to considered materials (Fig. 6). Spider silk, particularly flagelliform threads which are the most extensible, can extend up to $270 \%$ of its original length (at break), 27 for the dragline (Table 2). For comparison with our previous high-resistance fibers, Kevlar $^{\circledR} 29$ has a strain at break of 2.4\%, UHMWPE does not elongate further than 7\% (Dayyoub et al. 2019), Vectran ${ }^{\circledR} 3.8 \%$ (Ward 2012) and Zylon ${ }^{\circledR} 2.5 \%$ (Seely et al. 2004). Nylon 6 has a strain at break reaching $16 \%$, and steel is not considered as an elastic material (De Araújo 2011). Among the natural fibers, the exceptional elongation at break of spider silk once again dominates. Wool has a maximal observed strain at break of 44\% (Thompson and Hynd 2009), Bombyx' silk ( $\operatorname{maximum}=35 \%)($ Asrar and Hill 2002), PALF (maximum $=14.5 \%)($ Yan et al. 2016), cotton $($ maximum $=10 \%)$ (Yan et al. 2016), curaua (maximum $=4.9 \%$ ) (Yan et al. 2016), ramie (maximum $=5 \%$ ) (Kumar et al. 2020), flax (maximum $=3.3 \%$ ) (Yan et al. 2016). In terms of elasticity elastane dominates that category, with an elongation at break that can reach $610 \%$ (Senthilkumar et al. 2011); however, its ultimate tensile strength is nowhere close to the high values developed in 2.2.1. Indeed, textile industry uses blends of cotton and elastane, profiting from the higher strength and comfort of cotton. Spider silk is therefore a unique material that combines both mechanical properties in one polymer. It is also interesting to mention that post treatments of silk, such as addition of aqueous glues or water coating, can increase the elasticity and the plasticity of the polymer after its spinning (Vollrath and Edmonds xxxx; Wray et al. 2011).

\section{Spider silk, a good compromise}

We demonstrated that silk, although being a strong fiber, does not surpass synthetic filaments. However, the interest of silk and mostly of spider silk, resides in its versatility (Fig. 6). Where other materials possess either one strong feature or another, it is possible for silk to have both a resistant and elastic (or plastic) behavior (Huang et al. 2018). This is a characteristic of biopolymers, that results of the chemical bonds between the chains and their structure (see Sect. 1.2): the very developed network of hydrogen bonds between amino acids in the relaxed thread and the covalent bonds between proteins in the nanocrystalline regions as a safety backup when stretched (Nova et al. 2010). The ratio between resistance and elasticity for silk and mostly spider silk, is unique to considered materials (Fig. 6).

\section{Torsion and shape memory}

Although common understanding around shape memory suggests the implication of metallic alloys (Huang et al. 2010), which are mostly concerned by this property as they return to an original state after a thermal deformation, some polymers also behave as so. When twisted, the spider thread goes back to its original position, as do most of fibers like Kevlar $^{\circledR}$ or copper. But unlike these materials, who have a pendulum like movement before returning to their original equilibrium, spider silk returns to its pristine shape without oscillations thanks to its high damping coefficient. After a first torsional stress, the fiber shows a major energy dissipation (about 75\%) (Liu et al. 2017 Peculiar torsion dynamical response of spider dragline silk). This absence of swinging 


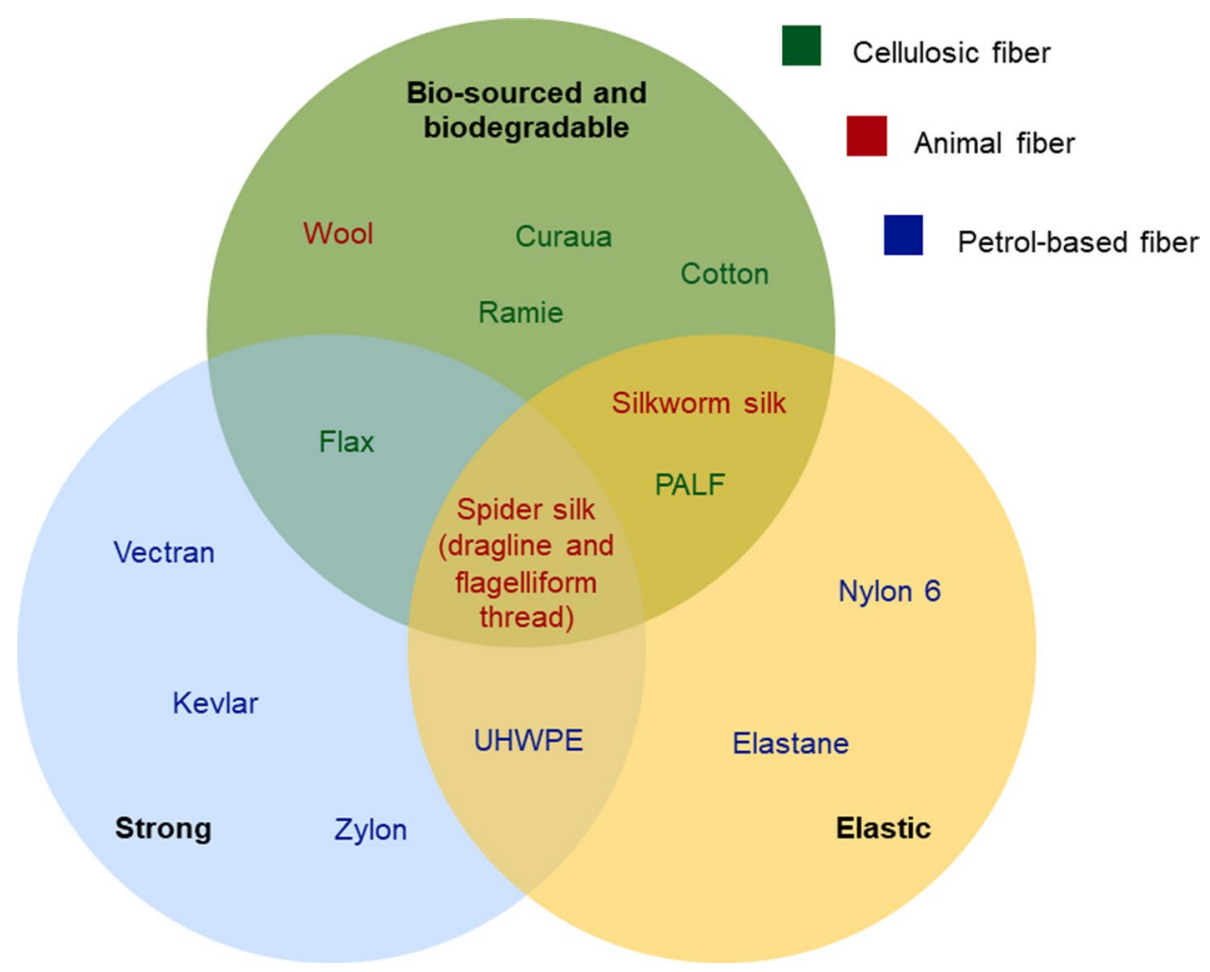

Fig. 6 Position of diverse fibers. Are considered strong materials with an average ultimate tensile strength over $0.95 \mathrm{GPa}$, elastic materials with a strain at break over $7 \%$. These thresholds were based on the median value of all our fibers' average numbers for each property. Of all fibers compared for their mechanical characteristics in this review, only spider silk (dragline and flagelliform threads) embodies a crossover between strength (values obtained for ultimate tensile strength), elasticity (values obtained for strain at break) and organic nature. The advantage of a bio-sourced fiber in comparison with petrolbased material, is that not only its synthesis is realized in water and without high energy input, but also its breakdown after use can be achieved in nature without toxic consequences for ecosystems. References for $\operatorname{Kevlar}^{\circledR}(n=2 / 2)$ (Quintanilla), Zylon ${ }^{\circledR}(n=3 / 3)$ (Seely

reduces the risks of dislocations and ruptures inside the protein chains; hence, the spider thread keeps its integrity after torsion and can even endure several torsional stresses without losing its mechanical properties. Recent studies even suggest a fatigueless and superelastic behavior, where the original nanostructure and detorsion capacities remain unchanged after thousands of twisting spins per $\mathrm{cm}$ of thread (Kumar and Singh 2014). Number of twisting cycles at breaking point is the highest in spiral threads, followed by dragline (Kumar et al. 2020). With this ability, spider silk can return to its original shape without any temperature modifications (Emile et al. 2006) (Fig. 7).

\section{Supercontraction}

Unlike other artificial polymers and even Bombyx mori's silk, spider dragline is capable of supercontraction in a humid environment (Work; Aguilar and San Román 2019). The maximum et al. 2004; Kumar et al. 2002; Zhang et al. 2018; Hao et al. 2019), Vectran $^{\circledR}(n=1 / 1)$ (Tanaka and Moritaka; Clements 1998; Ward 2012), UHWPE ( $n=1 / 1)$ (Ogawa et al.; Dayyoub et al. 2019), elastane $(n=1 / 1)$ (Senthilkumar et al. 2011), Nylon $6(n=4 / 4)$ (Rangari et al. 2008; Bhattacharyya et al. 2009), spider's silk $(n=4 / 4)$ (Heim et al. 2009; Teule et al. 2012), silkworm's silk $(n=13 / 18)$ (various sources referenced in) (Zhao et al. 2006), Curaua $(n=3 / 2)$ (Yan et al. 2016; Monteiro et al. 2010), PALF ( $n=2 / 2$ ) (Yan et al. 2016), Ramie ( $n=1 / 1)$ (Kumar et al. 2020), cotton $(n=2 / 2)$ (Yan et al. 2016), Flax $(n=2 / 2)$ (Yan et al. 2016; Zhu et al. 2013) and wool $(n=3 / 4)$ (Smith et al. 2014; Yükseloğlu et al. 2015). $n$ : number of gathered values per mechanical property (ultimate tensile strength/strain at break)

of supercontraction is reached for a dragline of Nephila clavipes at $70 \%$ of humidity. In these conditions, the thread shrinks up to $50 \%$ of its original length and generates a stress reaction up to $140 \mathrm{MPa}$. The rate of increase of the humidity in the air also plays a role in the supercontraction efficiency, an increase of $1 \% / \mathrm{s}$ doubles the stress response from the material (in comparison with a 2\%/s rate) (Agnarsson et al. 2009). When dry, the spider silk behaves as a glassy material: it shows a certain elastic behavior until it extends irrevocably and then breaks. This is due to the disruption of hydrogen bonds between the chains of proteins (in the amorphous regions), which can reform themselves after the tension applied on the fiber stops. When moisturized, the water plasticizes the amino acids chains and reduces the elastic modulus, which increases the elastic potential of the fiber before its plastic extension. During supercontraction, the thread is hence more extensible, slightly heavier, softened, swollen, and more ductile. This profile confers the fiber an useful feature: as a prey flies into 
Fig. 7 Pristine spider silk fiber (top) after moisturization (bottom), showing the shrinking effect of supercontraction. The hydration of the amorphous chains result in the creation of numerous hydrogen bonds between the protein domains, resulting in the overall contraction of the thread (Guinea et al. 2005; Dionne et al. 2017)

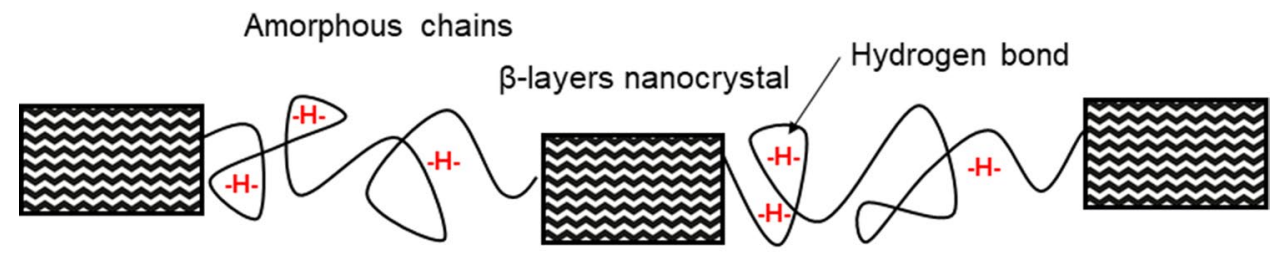

Plasticization and creation of more hydrogen bonds

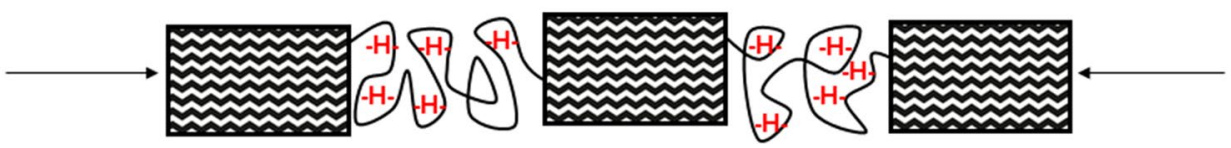

the web, the kinetic energy is better dissipated than it is in the dry material (Boutry and Blackledge 2013; Blamires and Sellers 2019). The drying of the supercontracted fiber results in a contracted thread that shows mechanical properties similar to superior to a pristine fiber once it is relaxed back to its original length (being less stiff, more extensible, more resistant and tougher) (Guinea et al. 2005; Blackledge et al. 2009). If not stretched after supercontraction, fibers tend to return to their original length within a time going from a few minutes to a few hours, but remain shorter than pristine ones (Elices et al. 2011). In spiral threads, from flagelliform glands, the changes of humidity also affect the silk, but in a different way: an increasing hygrometry swells the microscopic sticky droplets that confer the thread adhesivity (Opell et al. 2009), which rises the stickiness potential (Sahni et al. 2011). Also, these moisturized droplets act like water storage on the thread, which hydrates the silk even in low humidity context. The spiral threads are thus benefiting from a perpetual supercontracted state, hence their outstanding elasticity (Vollrath and Edmonds $\mathrm{xxxx}$ ). Interestingly, the supercontraction happens more efficiently under a fast increase of humidity reaching the threshold of $70 \%$, but the following air drying also generates some subsequent stress on the fibers. Blackledge et al. recorded stress peaks up to $140 \mathrm{MPa}$ in Nephila threads as the humidity gradient switched from high to low (below 50\%) after a first supercontraction phenomenon (Blackledge et al. 2009). This was characterized as a cyclic contraction process. Supercontraction is a unique property in spider silk. Artificial fibers have been designed to imitate such phenomenon, trying to reach the biomaterial's potential, with promising results (Shi and Yao 2020; Wu et al. 2018).

\section{Thermal properties}

\section{Thermal stability}

Spider silk are only completely degraded at more than $1000{ }^{\circ} \mathrm{C}$. The material keeps its integrity at $94 \%$ until the temperature of $230{ }^{\circ} \mathrm{C}$ and then drops (Cunniff et al. 1994), all previous weight loss being due to water evaporation. The analysis of crystals in the fibroin chains of the spider silk under heating showed that there is a destruction in the first type of crystals from $100{ }^{\circ} \mathrm{C}$ and $350{ }^{\circ} \mathrm{C}$ for the second type in Nephila spider silk (Sheu et al. 2004), respectively, 250 and $260{ }^{\circ} \mathrm{C}$ for Bombyx mori's silk (Lu et al. 2011). Moreover, the tensile behavior of the spider fiber remains almost unchanged from ambient temperature to $150{ }^{\circ} \mathrm{C}$. Interestingly however, the ultimate tensile strength and strain at break show remarkable increases when the temperature gets negative: up to twice their potential at $25^{\circ} \mathrm{C}$ when they reach $-60{ }^{\circ} \mathrm{C}$ and $63 \%$ stronger at $-196{ }^{\circ} \mathrm{C}$ than at room temperature. The toughness of the fiber is also enhanced by lower temperatures (Yang et al. 2005). Fibers that achieved supercontraction at least once suffer molecular degradation at lower temperatures than pristine ones, with a significant difference between 350 and $450{ }^{\circ} \mathrm{C}$ (Blackledge et al. 2009). For comparison purposes and although these materials are used for their resistance to frictions, Nylon 6 is not degraded until $150{ }^{\circ} \mathrm{C}$, Kevlar ${ }^{\circledR}$ until $250{ }^{\circ} \mathrm{C}$ (Li and Huang 1999), making Kevlar ${ }^{\circledR}$ the closest homologue to silk. Some very high texturized fiberglass fibers like Zetex ${ }^{\circledR}$, or PBI (polybenzimidazole), novoloid, polyphenylene sulfide fibers, can resist temperatures between $260{ }^{\circ} \mathrm{C}$ and $1095{ }^{\circ} \mathrm{C}$ (Raheel 1994). However, their mechanical properties might be affected under long exposure to such heat.

\section{Thermal conductivity}

Unlike most of comparable polymers, silk also shows a remarkably high thermal conductivity. As this parameter depends on the alignment of the protein chains, it also increases when the fiber is stretched, going from 349 in the relaxed state ( $3.9 \%$ of elongation) to $416 \mathrm{~W} \mathrm{~m}^{-1} \mathrm{~K}^{-1}$ (19.7\% of elongation) in Nephila clavipes dragline (Huang et al. 2012). In terms of thermal properties, spider silk hence differs from other polymers, even from silkworm's silk, who has a low thermal conductivity about $4.7 \mathrm{~W} \mathrm{~m}^{-1} \mathrm{~K}^{-1}$ in optimal conditions (Huang et al. 2012), Kevlar ${ }^{\circledR}$ 
$\left(0.04 \mathrm{~W} \mathrm{~m}^{-1} \mathrm{~K}^{-1}\right)$, or Nylon $6\left(0.25 \mathrm{~W} \mathrm{~m}^{-1} \mathrm{~K}^{-1}\right)$ (King et al. 2004). Only carbon nanotubes possess a largely higher thermal conductivity, reaching $6000 \mathrm{~W} \mathrm{~m}^{-1} \mathrm{~K}^{-1}$ (Collins and Avouris 2000).

\section{Electrical properties}

\section{Electrical conductivity}

Silk by itself is a relatively poor conductor for electricity and can only provide scaffold fibers for other conductors (Steven et al. 2013). The conductivity of such an hybrid structure however depends on the relative humidity of the context, from $40 \%$ of humidity, the conductivity of the fiber will increase linearly (Steven et al. 2011). Conductivity also depends on the coating of the thread, studies so far describe threads coated with iodine, carbon nanotubes or gold, giving possibilities for the hybrids material to ally spider silk mechanic characteristics and conductivity of well-known superconductors (Steven et al. 2011). Both spider and Bombyx silk have been hybridized with other materials, respectively, carbon nanotubes and BEDT-TTF (based organic molecular conductor) and shown the unique properties of the silks topping the conductivity of these materials (supercontraction, elasticity, resistance, thermic properties) (Steven et al. 2014). Spider silk's fibroin has also been used in the conception of electronical devices (memristor) for its biodegradable features and ease of preparation (Sun et al. 2015).

\section{Piezoelectrical properties}

Silk fibroin, as a semi-crystalline biomaterial, shows shear piezoelectricity, at a level of about $1 \mathrm{pC} / \mathrm{N}, 0.36 \mathrm{pC} / \mathrm{N}$ for spider fibroin (Karan et al. 2018). For comparison, quartz shows the similar behavior with $2 \mathrm{pC} / \mathrm{N}$ (Yucel et al. 2011) and currently leading piezoelectrical material LZT or PZT (lead/plumb zirconate titanate) 100 to $1300 \mathrm{pC} / \mathrm{N}$. Yucel et al. (Yucel et al. 2011) established that the abundance of crystalline structures in beta-sheets of fibroin was correlated with its piezoelectrical activity. Despite its relatively low range, silk could find applications in several domains. It figures among the several non-toxic, biodegradable and biocompatible materials that are currently used for biomedicine, like cellulose paper, PVDF (polyvinylidene difluoride) and aluminum nitride (Sappati and Bhadra 2018). Aluminum nitride films on PET's piezoelectric response has been reported by Akiyama et al. to reach $0.7 \mathrm{pC} / \mathrm{N}$, with application for pressure sensors, namely human pulse (Akiyama et al. 2006). With a comparable activity and similar fits for such applications, silk could stand as an alternative: in 2018, Karan et al. worked on another type of application for spider silk: self-charging devices. The conversion of mechanical energy into electrical power through the piezoelectric behavior of spidroins has been described as remarkable and could lead to the design of nano-generator using the body natural motion to function (Karan et al. 2018).

\section{Biocompatibility}

Over the past decades, silkworm's silk has been studied for its biocompatibility in order to create biomaterial for tissue regeneration (Krishna et al. 2010). The biopolymer, ridden of its sericin coating (crucial step to prevent infections and rejection (Altman et al. 2003)), presents the qualities of a porous scaffold for cell growth. Pristine pure fibroin is relatively well accepted by the biological structures, as its presence do not trigger an immune reaction, nor does it lose its semi-crystalline structure. Its cytocompatibility is higher than synthetic tissue culture polystyrene, commonly employed for that use (Wray et al. 2011; Lerman et al. 2018). Spider's egg sac silk also shows advantages for biomedical uses; after enzymatic cleaning, the fibers have higher biocompatibility, can resist heavy loads (like organic tissues) (Gellynck et al. 2008) and keep their toughness in aqueous environments (Viney). Both polymers, spider and silkworm's silk, have shown very slow degradation throughout time in aqueous conditions. Both also surpass some other synthetic homologues like Vicryl ${ }^{\circledR}$ (polyglycolic acid) in the maintenance of their mechanical properties (Gellynck et al. 2008).

\section{Electrospinning of silks}

Just as we understand the exceptional potential of silk whether it is for its chemical structure, its versatile mechanical properties or its biocompatibility, various techniques are employed to create derived materials. Silks are used in gels, fibers, sponges, resins, powders, films, for also various purposes in numerous domains (Basu 2015). Of all, electrospinning resembles our biological models the most: for the nano-spinning of a continuous fiber hardened from a liquid proteinic dope (Li et al. 2003). Different authors even started to mimic the perfected skill of the spinning spider. Among them, in 2008, He et al. got inspired to create an electrospinning process (known as bubble electrospinning) that reproduces the spinning dope bubbles that a spider produces at the tips of the microtubules before the shearing of the fiber (He et al. 2008). Viscosity of the spinning dope and temperature of spinning are now to be adjusted. In 2009, Jirsak et al. invented a variant method of conventional electrospinning that could produce industrial quantities of electrospun material, instead of the gram/hour quantities currently reached by the process (Jirsak et al. 2009). Unlike conventional electrospinning, the technique projects several silk streams at the same time, mimicking the spider's 
fibroin nanofibrils (Sasithorn and Martinová). Although for now, mostly conventional electrospun silk's outcomes have been investigated, industrial and yet biomimetic production of the material might be a reality tomorrow. Additionally, electrospinning technique is most commonly used to design substrates for applications such as cell growth, protection and embedment of sensors or drugs (drug delivery). Considering the advantages of silk and their subsequent potential applications, our biopolymer's strengths and these listed applications are a functional match, electrospinning silk is therefore relevant (Kumar et al. 2018).

\section{Electrospinning advantages}

Electrospinning, unlike weaving methods, allows the obtention of large specific surface of nonwoven textile with a very thin scale, down to tens of nanometers (Bognitzki et al. 2001). It is a technic that compiles ease of use and possibility of large-scale production. The interest of such a small level of design is that determination of porosity (and size of pores), morphology (alignment, diameter) of fibers and other emergent properties (integration of sensors) is potentially very precise (Li and Xia 2004; Agarwal et al. 2008). Interestingly, modifying the setup of the electrospinning apparatus lead to different types of fibers, where the optical, magnetic, electronic and biological properties vary. It is even possible to use specific spinnerets to create a range of secondary structures, like hollow fibers, or cores coated with a different polymer. The electromagnetic fields that apply on the projected fiber not only reduce its diameter, but can also determine a targeted area for the textile to be locally thickened (Li and Xia 2004; Zhang and Chang 2008). The electrospun scaffolds usually share a compatibility with biological tissues, and can even mimic histological structures, even though its applications do not stop to biopolymers (Nune et al. 2017). Hybrid spinning dopes have already been successfully electrospun, optimizing the properties of both polymers, like bicomposites of organic and synthetic compounds (Stankus et al. 2008).

\section{Electrospinning basics}

Electrospinning is a spinning technique using an electrical input to create a fiber from a polymer solution. Unlike regular spinning processes, this method allows the creation of scaffolds and mats with a nanometric scale (fibers and pores) (Leach et al. 2011), regularity of the texture, outstanding surface properties and thinness of the produced material (Knapczyk-Korczak et al. 2020).

The universal setup for electrospinning includes, as illustrated in Fig. 8, a syringe filled with a polymer solution. The injection pump presses the solution at a defined speed, forming a droplet at the tip of the needle. A source of power creates an electrical field between the needle and the collector screen, surpassing the surface tension of the liquid droplet. This results in the formation of the Taylor cone and the projection of a nanometric fiber through the air. The fiber eventually lands in a random order on the collector (Mitchell and Tojeira; Shin et al. 2012). While the polymer fiber is projected in the air towards the collector, the solvent that kept it in a liquid phase evaporates, reducing the diameter of the fiber to the nanometric level (Sukigara et al. 2004). The collector can be rotated all along the process, to create the mesh on a larger surface. External parameters while operating electrospinning influence the quality of the final spun sample. The humidity of the air and the temperature must be kept constant and monitored, thus, a confined experimental area is recommended. A flow cabinet also prevents the inhalation of toxic fumes (from the solvents) during the process (Lang et al. 2013).

\section{Obtention of silk proteins}

Before electrospinning, the spinning dope must be prepared out of fibroin proteins. The obtention of these proteins varies depending on the sources (Fig. 9). Most of silk electrospinning protocols work with Bombyx mori silk. The polymer is directly extracted from insects' cocoons. The pupas can be bought from life sciences and
Fig. 8 Setup for silk electrospinning. The injection pump pulls the polymer solution in the syringe, linked to a conductor. The high-voltage input creates a cone of Taylor at the tip of the needle. The stream jet is propelled through the air in a random manner and stacks in a nonwoven canvas on the collector

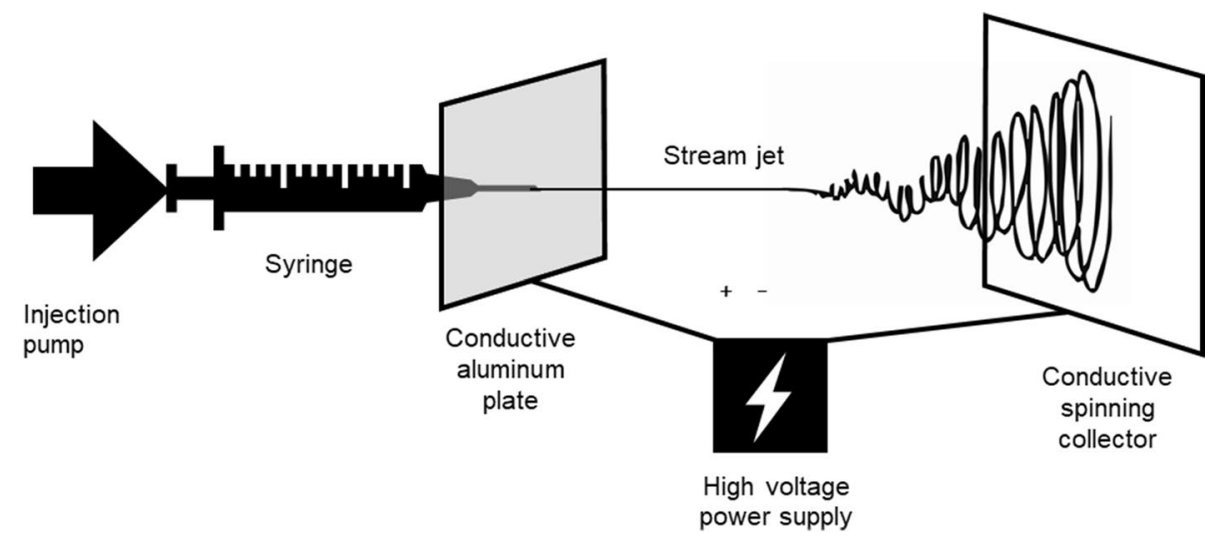


biotechnology companies, or from sericulture farms. In the case of spidroins, protocols including web harvests from live animals exist, but are rather rare (Zarkoob et al. 2003; Zhou et al. 2008), due to the difficult production of necessary quantities as spiders do not naturally live in groups. Most of studies make use of recombinant spider fibroin, like ADF-3, ADF-4, pNSR16, MaSp1 (Peng et al. 2016) and MaSp2, that call for hosts as feedstock for silk protein production (Xu et al. 2018). These are the proteins issued from the expression of Nephila clavipes' genes regulating the fibroin production. These genes have been transferred into silkworms' genomes so that they could synthetize their cocoon out of a silk that would have the qualities of spider silk. This recent technique, allowed by the improvement of biotechnologies and the possible combination between silkworm and spider's fibroin, is among the most efficient with more than $30 \%$ of the produced silk being spidroin (Xu et al. 2018). Also, as the obtained product resembles a natural silkworm's cocoon, further manipulations can follow well-described protocols for Bombyx silk. However, other groups have worked with proteins issued from different vectors, like genetically modified E.coli (Leal-Egaña et al. (2011); Lang et al. 2013; Peng et al. 2016), or other prokaryotic vectors (Zhao et al. 2017), goat milk (Kandas et al. 2018), yeasts or plant vectors (Vendrely and Scheibel 2007; Xu et al. 2018), with various applications (Table 3 ) and (respectively decreasing) yields (Fig. 9).

\section{Electrospinning of silkworm's silk}

\section{Degumming the silk}

The first step in the electrospinning of a polymer, is the preparation of the spinning dope. Electrospinning of silk of Bombyx mori has been described in several studies these last decades, for the fabrication of nonwoven mats with applications in filtration or biomedicine (Vepari and Kaplan 2007). Working from scratches, with silkworms' cocoons, the first step consists of degumming the silk, removing the sericin coating from the fibroin core. This is necessary to reach the maximal resistance features and also provides the final material more luster and softness. Degumming can be achieved through several processes, with soap (Marseille soap (Ohgo et al. 2003)) and water, using proteases, or alkaline solution (Gulrajani 1992), but most recent studies advise a simple boiling, at $90{ }^{\circ} \mathrm{C}$ in water for $60 \mathrm{~min}$ (Altman et al. 2003). Works on Antheraea pernyi, another silkworm, suggest the use of $2.5 \mathrm{~g} / \mathrm{L}$ aqueous solution of $\mathrm{NaCO}_{3}$, to boil three separate times the silk cocoons during 30 to $45 \mathrm{~min}$ (100 g of cocoons for $5 \mathrm{~L}$ of solution) (Tao et al. 2007). Degummed silk fibers must be dialyzed overnight in demineralized water and dried under a flow until lyophilization (possibly heated to $60{ }^{\circ} \mathrm{C}$ ) (Tao et al. 2007).

\section{Issolution and solubilization of the fibroin fibers}

Before electrospinning the silk fibers, it is necessary to dissolve them into a first solvent and suspend them in a second one, that will be the spinning dope. Working directly from the glands of the silkworm (studies on Antheraea mylitta), it is possible to directly dissolve and suspend fibroin proteins in a solvent, SDS (sodium dodecyl sulfate) $1 \%$ (in $10 \mathrm{mM}$ Tris pH8 and $5 \mathrm{mM}$ EDTA) (Mandal and Kundu 2008). Working from degummed silk cocoons, fibroin fibers are dissolved in a solvent, like $\mathrm{LiBr}$ (Inouye et al. 1998), $\mathrm{Ca}\left(\mathrm{NO}_{3}\right)_{2}$ (Altman et al. 2003), or aqueous $\mathrm{CaCl}_{2}$ (Ayutsede et al. 2005) and dried and lyophilized under a flow or by heating at $60^{\circ} \mathrm{C}$ (Tao et al. 2007). After lyophilization, the fibroin sponge is dissolved in formic acid (Sukigara et al.), possibly supplemented with small amounts of $\mathrm{CaCl}_{2}$ (Vepari and Kaplan 2007), or in hexafluoroisopropanol, or in HFAhydrate solution (Ohgo et al. 2003), or simply in water (Zhou et al. 2009), but for short periods of time (Altman et al. 2003). Electrospinning parameters, including dope concentration, remain at the appreciation of the operator. Changes in solvents, or slight differences in the device features can modify the outcome. It has been demonstrated, for example, that a higher concentration of the dope generates thicker fibers with less beads (Zhang et al. 2009).

\section{Spinning of the dope}

Once solubilized, the fibroin solution is filled into the syringe for electrospinning. Bombyx mori silk is spun in a needle at a definite spinning angle. The spinning distance from the needle to the collector varies depending on uses (Table 3), with a voltage between 10 and $35 \mathrm{kV}$ (references in Table 3). This, however, depends on the type of solvent used for the solubilization of the fibroin and must be adjusted depending on the operator's live appreciation (Zhou et al. 2009; Leach et al. 2011). The flow rate is set between 0.2 and $4 \mathrm{~mL} / \mathrm{h}$ (Pang et al. 2019; Shehata et al. 2019), at ambient temperature, and air humidity adjusted by the flow cabinet, remaining under 30\% (Meinel et al. 2009). After spinning, the obtained mat is immersed in a bath of methanol or ethanol for various times (Min et al. 2004) and dried. The effects of these compounds and their time of application on the mechanical characteristics have been well assessed by Amiralyan et al. (Amiraliyan et al. 2010). This induces the crystallization of the fibers (Zhou et al. 2009; Zhang et al. 2012) and also reduces the porosity of the mat (Vepari and Kaplan 2007). Another possible post-treatment implies the exposition of the mat to glutaraldehyde (GA), to modulate physico-chemical properties 
Table 3 Electrospinning parameters for pure and hybrid fibroin mats, used in diverse applications. The fibroin is issued from silkworm's cocoons, recombinant eADF4(C16), pNSR16, or MaSp1 and MaSp2 spider silk proteins, or natural spider silk

\begin{tabular}{|c|c|c|c|c|c|c|c|c|}
\hline $\begin{array}{l}\text { Type of silk/ } \\
\text { dope }\end{array}$ & $\begin{array}{l}\text { Dope con- } \\
\text { centration in } \\
\text { fibroin }(\%)\end{array}$ & $\begin{array}{l}\text { Spinning } \\
\text { solvent }\end{array}$ & $\begin{array}{l}\text { Flow rate } \\
(\mathrm{mL} / \mathrm{h})\end{array}$ & Voltage (kV) & Distance $(\mathrm{cm})$ & Needle (G) & Mat usage & References \\
\hline $\begin{array}{l}\text { Bombyx mori } \\
\text { fibroin }\end{array}$ & 12 & Formic acid & - & 12 & 10 & 22 & $\begin{array}{l}\text { Bone regen- } \\
\text { eration }\end{array}$ & Ki et al. (2008) \\
\hline $\begin{array}{l}\text { Bombyx mori } \\
\text { fibroin }\end{array}$ & 9 to 15 & Formic acid & - & 30 & 10 & 18 & $\begin{array}{l}\text { Experimental } \\
\text { characteriza- } \\
\text { tion }\end{array}$ & $\begin{array}{l}\text { Ayutsede et al. } \\
\quad(2005)\end{array}$ \\
\hline $\begin{array}{l}\text { Bombyx mori } \\
\text { fibroin }\end{array}$ & 37 to 41 & Water & - & 18 to 35 & 18 to 30 & - & Tubular grafts & $\begin{array}{l}\text { Zhou et al. } \\
\text { (2009) }\end{array}$ \\
\hline $\begin{array}{l}\text { Bombyx mori } \\
\text { fibroin and } \\
\text { PEO }\end{array}$ & 12.5 & $\begin{array}{l}\text { Ultra-purified } \\
\text { water }\end{array}$ & 1.2 & 12 to 15 & 19 & - & Cell growth & $\begin{array}{l}\text { Meinel et al. } \\
\text { (2009) }\end{array}$ \\
\hline $\begin{array}{l}\text { Bombyx mori } \\
\text { fibroin and } \\
\text { PEO }\end{array}$ & 7.5 & Water & 1.8 & 12.5 & 21.5 & 14.5 & $\begin{array}{l}\text { Bone marrow } \\
\text { culture }\end{array}$ & Jin et al. (2004) \\
\hline $\begin{array}{l}\text { Bombyx mori } \\
\text { fibroin, PEO } \\
\text { and hPL }\end{array}$ & 6 & Water & 1.2 & 23 & 30 & 19 & Drug delivery & $\begin{array}{l}\text { Pignatelli et al. } \\
\text { (2018) }\end{array}$ \\
\hline $\begin{array}{l}\text { Bombyx mori } \\
\text { fibroin, PEO } \\
\text { and EGF }\end{array}$ & 8 & Water & 1.2 & 10 to 11 & 15 to 21 & 14.5 & $\begin{array}{l}\text { Wound dress- } \\
\text { ing with } \\
\text { epidermal } \\
\text { growth } \\
\text { factor }\end{array}$ & $\begin{array}{l}\text { Schneider et al. } \\
\text { (2009) }\end{array}$ \\
\hline $\begin{array}{c}\text { Bombyx mori } \\
\text { and gelatin }\end{array}$ & 13 & Formic acid & 0.03 & 16 & 13 & 23 & $\begin{array}{l}\text { Experimental } \\
\text { characteriza- } \\
\text { tion }\end{array}$ & $\begin{array}{l}\text { Mohammadza- } \\
\text { dehmoghadam } \\
\text { and Dong } \\
\text { (2019) }\end{array}$ \\
\hline $\begin{array}{l}\text { Bombyx mori } \\
\text { and } \mathrm{TiO}_{2}\end{array}$ & 20 to 21 & Water & 1 & 19 to 20 & 42 & - & $\begin{array}{l}\text { Pesticide pho- } \\
\text { tocatalytic } \\
\text { degradation }\end{array}$ & $\begin{array}{l}\text { Aznar-Cer- } \\
\text { vantes et al. } \\
(2020)\end{array}$ \\
\hline $\begin{array}{l}\text { Bombyx mori } \\
\text { and fluores- } \\
\text { cent dyes }\end{array}$ & 6 to 10 & Formic acid & 0.2 & 15 & 15 & 18 & $\begin{array}{l}\text { Fluorescent } \\
\text { textile }\end{array}$ & $\begin{array}{l}\text { Pang et al. } \\
\text { (2019) }\end{array}$ \\
\hline $\begin{array}{l}\text { A.labyrin- } \\
\text { thica } \text { spider } \\
\text { fibroin, } \\
\text { PDLLA }\end{array}$ & 11 & - & - & 15 to 30 & 15 & 20 & $\begin{array}{l}\text { Experimental } \\
\text { characteriza- } \\
\text { tion }\end{array}$ & $\begin{array}{l}\text { Zhou et al. } \\
\text { (2008) }\end{array}$ \\
\hline $\begin{array}{l}\text { Recombinant } \\
\text { spider fibroin }\end{array}$ & 3 to 5 & Tris/HCl & 0.42 & 15 & 18.5 & 18 & $\begin{array}{l}\text { Experimental } \\
\text { characteriza- } \\
\text { tion and GFP } \\
\text { bounding }\end{array}$ & $\begin{array}{l}\text { DeSimone et al. } \\
\text { (2020) }\end{array}$ \\
\hline $\begin{array}{l}\text { Recombinant } \\
\text { spider fibroin }\end{array}$ & 10 to 15 & HFIP & 0.42 & 22.5 & 18.5 & 18 & & \\
\hline $\begin{array}{l}\text { Recombinant } \\
\text { spider fibroin }\end{array}$ & 4 to 24 & HFIP & 0.42 & - & 18 & 18 to 22 & $\begin{array}{l}\text { Fibroblasts } \\
\text { culture }\end{array}$ & $\begin{array}{l}\text { (Leal-Egaña } \\
\text { et al. 2011) }\end{array}$ \\
\hline $\begin{array}{l}\text { Recombinant } \\
\text { spider fibroin } \\
\text { and polyvi- } \\
\text { nyl alcohol }\end{array}$ & 15 & Formic acid & 3 to 7 & 80 to 100 & 18 to 22 & 20 & $\begin{array}{l}\text { Wound dress- } \\
\text { ing }\end{array}$ & $\begin{array}{l}\text { Zhao et al. } \\
\text { (2017) }\end{array}$ \\
\hline $\begin{array}{l}\text { Recombinant } \\
\text { spider fibroin }\end{array}$ & 10 & HFIP & 0.315 & 22.5 & 8 to 20 & 20 & $\begin{array}{l}\text { Air filtering } \\
\text { device }\end{array}$ & $\begin{array}{l}\text { Lang et al. } \\
\text { (2013) }\end{array}$ \\
\hline $\begin{array}{l}\text { Recombinant } \\
\text { spider fibroin } \\
\text { and cerium } \\
\text { oxide }\end{array}$ & - & - & 1 & 26 & 10 & 30 & $\begin{array}{l}\text { Optical fluo- } \\
\text { rescent mat }\end{array}$ & $\begin{array}{l}\text { Kandas et al. } \\
\text { (2018) }\end{array}$ \\
\hline
\end{tabular}




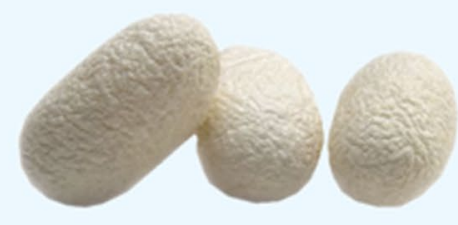

Bombyx mori silk cocoons or other silkworms

Degumming:

Boiling in water or in aqueous solution of

$\mathrm{Na}_{2} \mathrm{CO}_{3}$, alkaline solution, soap

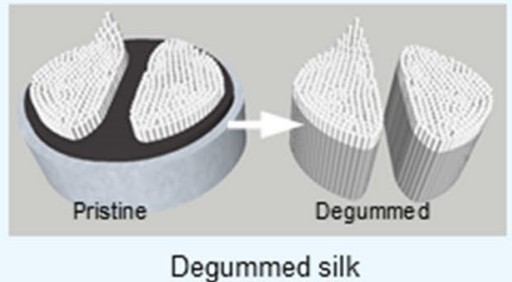

Degummed silk

Dissolution:

Boiling/stirring in aqueous solution of

$\mathrm{Ca}\left(\mathrm{NO}_{3}\right)_{2}$, or $\mathrm{LiBr}, \mathrm{C}_{2} \mathrm{H}_{5} \mathrm{OH}$ or $\mathrm{CaCl}_{2}$

Dialyze and lyophilization

Solubilization:

In formic acid and $\mathrm{CaCl}_{2}$, water or HFIP

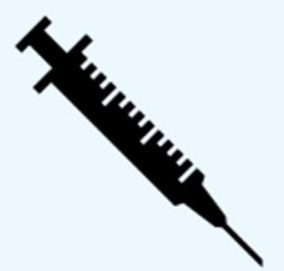

Parameters: concentration, needle, angle, voltage, distance needle-collector, flow rate

Post treatments:

In methanol or ethanol, and dried

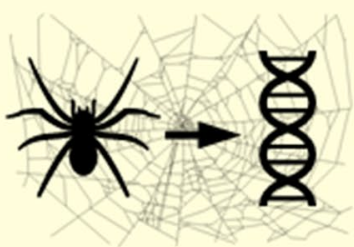

Recombinant fibroin proteins from spiders

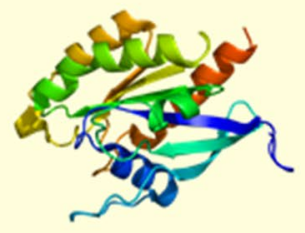

Fibroin protein eADF4(C16)

\section{Solubilization:}

HFIP, CTAB, formic acid or

Tris/ $\mathrm{HCl}$, and viscosity adjusters

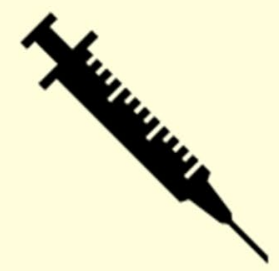

Parameters: concentration, needle, angle, voltage, distance needle-collector, flow rate

Post treatments :

Ethanol sprayed, and dried of fibers and their biocompatibility (Mohammadzadehmoghadam and Dong 2019). Sukigara et al. 2004 deeply investigated the outcoming diameters through varying the concentration of the dope and the electric field for silk electrospinning. The radiant correlation between these parameters and the obtained fiber can help choosing 
4Fig. 9 Protocols for solubilization of silk proteins from silkworms (left) and spidroins (right). Degumming and dissolution of silk are necessary for silkworm cocoons, and very rarely observed in spider think electrospinning, as the proteins are obtained from recombinant spider silk instead of natural fibers (Table 3). Degumming consists of washing the sericin off the silkworm's silk often achieved in an alkaline detergent solution, sericin being a glue-like protein with little biocompatibility (Altman et al. 2003). Solvents used for preparation of the spinning dope vary depending on the type of silk: for silkworm's silk, the solvent can be formic acid or HFIP (Table 3), but biomedical applications prefer water, for spider's silk, the organic solvent HFIP is the most used, but DeSimone et al. suggested an aqueous spinning dope based on the use of Tris/HCl (DeSimone et al. 2020). Post-treatments include vaporization or bath of methanol, water or ethanol (Min et al. 2004; Lang et al. 2013),

the best electrospinning program (Sukigara et al. 2003). Eventually, the length of the unique spun fiber can reach over $1000 \mathrm{~km}$ (Amiraliyan et al. 2010).

\section{Electrospinning of spider's silk}

Spider silk, unlike Bombyx mori's, is usually found in late researches as a recombinant protein, known as eADF4(C16). This protein originates from the genes of Araneus diadematus for fibroin synthesis, and therefore does not require a degumming treatment, since it is already lacking sericin (Lang et al. 2013; DeSimone et al. 2020). In the rare studies where natural spider web have been used, the silk (from Agelena labyrinthica) has been rinsed several times in distilled water and then purified in acid formic at $70{ }^{\circ} \mathrm{C}$ for 7 days, before being mixed with PDLLA and electrospun (Zhou et al. 2008). In other works, purified fibroin proteins are dissolved in hexafluoroisopropanol (Lang et al. 2013) possibly in addition with formic acid and hexadecyl trimethyl ammonium bromide (Shehata et al. 2019), or $10 \mathrm{mM}$ Tris/HCl pH 7.5 with addition of PEO400 (DeSimone et al. 2020). They are filled into a syringe. The basic functioning of the electrospinning device is the same as in Bombyx's silk spinning, with the following parameters: 8 to $20 \mathrm{~cm}$ of distance between the needle and the collector, needle voltage between 15 and $30 \mathrm{kV}$, flow rate between 0.32 and $0.4 \mathrm{~mL} / \mathrm{h}$, air humidity between 15 and $60 \%$ (Lang et al. 2013; DeSimone et al. 2020), ambient temperature. Here again, the parameters are up to the appreciation of the operator, for the formation of a steady cone of Taylor and a regular flow (Leach et al. 2011). Post-treatment of the obtained mat includes spraying of ethanol for $90 \mathrm{~min}$ at $60{ }^{\circ} \mathrm{C}$ (Lang et al. 2013). In the case where PEO has been used as a stabilizing additive for the spinning, it is removable from the mat by water rinsing, as PEO is soluble in water, and spider silk is not (Shehata et al. 2019).

\section{Choice of solvents}

Regarding the possible applications of silk non-woven mats, a majority of them being in biomedical and regenerative medicine domains, it is important to choose solvents that are life friendly. Not only saving some detoxifying stages from the protocols, a green solvent is also safer for the user during manipulation. Some of the mentioned solvents for degumming and dissolution are mildly irritating for human skin because of their basicity and detergent potential, such as $\mathrm{NaCO}_{3}$ or Marseille soap, or SDS, but not dangerous for environment. De Simone et al. recommended in their experiments the use of Tris/HCl buffer and PEO400 instead of hexafluoroisopropanol, because of the relative safety of manipulation of this aqueous protocol and compatibility with organic tissues without further post treatments (Desai et al. 2019; DeSimone et al. 2020; Salehi et al. 2020). It is worth mentioning that although the use of PEO allows more stability in the viscosity parameter during the electrospinning process, its employ requires its elimination as a post treatment, through heating the mat to $100^{\circ} \mathrm{C}$, hence increasing the energy input of this protocol (Jin et al. 2004). Also, the use of a setup such as bubble electrospinning (He et al. 2008) instead of traditional electrospinning can fix some issues in this viscosity stability. Finally, formic acid, used in most of protocols as a final solvent for the spinning dope, must be used with precautions as it is corrosive for lungs, skin, eyes, etc.

\section{Obtained results}

\section{Bombyx silk's mats}

Electrospun mats of Bombyx mori were successfully synthetized in literature. Reported ultimate tensile strength and strain at break were, respectively, between 13.6 and $14 \mathrm{MPa}$ and between 4 and 40\% (Table 4) (Ohgo et al. 2003). Studies led on electrospun Bombyx mori's silk reveal that the numerous spinning parameters are affecting the final mat's features. Molecular weight of the spinning dope, solvents used, and post-spinning treatments highly influence the mechanical properties such as ultimate tensile strength and strain at break (Zhang et al. 2012). Postspinning dipping in methanol under heating contributes to shrink the fibers and hence reduce the overall porosity of the mat, which rises to 68\% (Min et al. 2004). Parameters of electrospinning influence the final result: distance of spinning, concentration of the dope, voltage, and flow rate affect the morphology of the fibers, including its diameter. A low concentration leads to fibers bearing beads, poorly smooth, whereas a high concentration creates continuous and uniform fibers (Min et al. 2004; Zhang et al. 2012). Characterization of mats has not been described 
Table 4 Characteristics of non-woven mats made out of silkworm silk dope. Spider silk mats

\begin{tabular}{|c|c|c|}
\hline Characteristic & Bombyx mori & References \\
\hline Fiber diameter $(\mathrm{nm})$ & 6.5 to 6100 & $\begin{array}{l}\text { Zarkoob et al. (2003); Min et al. (2004); Ayutsede et al. (2005); Meinel et al. (2009); } \\
\text { Aznar-Cervantes et al. (2012); Zhang et al. (2012) }\end{array}$ \\
\hline Morphology & $\begin{array}{l}\text { Beads to cylindrical } \\
\text { (low dope concentra- } \\
\text { tion) } \\
\text { Continuous to ribbon- } \\
\text { like (high concentra- } \\
\text { tion) }\end{array}$ & Min et al. (2004); Zhang et al. (2012) \\
\hline Ultimate tensile strength $(\mathrm{MPa})$ & 13.5 to 74 & $\begin{array}{l}\text { Jin et al. (2004); Amiraliyan et al. (2010); Yi et al. (2018); Mohammadzadehmogh- } \\
\text { adam and Dong (2019) }\end{array}$ \\
\hline Strain at break $(\%)$ & From 4 to 40 & $\begin{array}{l}\text { Ohgo et al. (2003); Jin et al. (2004); Amiraliyan et al. (2010); Zhang et al. (2012); } \\
\text { Mohammadzadehmoghadam and Dong (2019) }\end{array}$ \\
\hline Porosity $(\%)$ & 62 to 68 & Min et al. (2004); Mohammadzadehmoghadam and Dong (2019) \\
\hline Water uptake capacity $(\%)$ & 405 & Mohammadzadehmoghadam and Dong (2019) \\
\hline Temperature of degradation $\left({ }^{\circ} \mathrm{C}\right)$ & 250 & Pang et al. (2019) \\
\hline
\end{tabular}

extensively, no more than their comparison with pristine silk's mechanical properties. Most of the studies rather focused on the efficiency of the mats in their respective applications, such as biocompatibility for example.

Although natural spider silk is composed of thinner threads than Bombyx mori's cocoons, literature suggests that the minimal diameter observed in electrospun mats rises to $8 \mathrm{~nm}$ (Zarkoob et al. 2003) and can reach more than $1000 \mathrm{~nm}$ in certain spinning conditions (Table 5) (Zhou et al. 2008). Here again, spinning parameters affect the fibers' final topography and therefore the few obtained results might not be the full possible spectrum. Tests realized on aligned electrospun fibers of recombinant spider's fibroin (known as MaSp1) indicate an ultimate tensile strength of 9.6 MPa, and an strain at break of $14.3 \%$ of the obtained mats. Most of studies led on electrospun spider silk actually concern composites, as engineers aims to compile the mechanical advantages of a certain material (like extremely resistant carbon nanotubes) and the diverse features of spider silk (see Sect. 2). Just like for silkworm's silk mats, mechanical characterization values have barely been reported so far.

\section{High value applications for electrospun silk}

It has been made clear (see Sect. 2.) that silk and even more spider silk possess unique properties which are employed into multiple applications. Electrospinning silk remains nevertheless a recent technology. Characterization of obtained mats is not standardized into common protocols, and it is unsure in literature if the values observed for mechanical (and other) characteristics of silk are preserved in the electrospun products, for the very structure of the fiber is modified through this method. Nevertheless, applications exist and are reviewed below.

\section{Biomedical applications}

\section{Wound dressing}

As silk has been used for millennia to stop bleeding and wrap wounds (Salehi et al. 2020), electrospun fibers of silkworm (Schneider et al. 2009; Wharram et al. 2010) and spider silk (Zhao et al. 2017) was tested to be an efficient material for wound dressing. The proper dressing for an open injury or a burn to heal correctly requires protection

Table 5 Characteristics of electrospun spider silk mats

\begin{tabular}{lll}
\hline Characteristic & Spider silk & References \\
\hline Fiber diameter (nm) (Nephila Clavipes) & 8 to 1200 & Zarkoob et al. (2003); Zhou et al. (2008) \\
$\begin{array}{l}\text { Morphology (at } 80 \mathrm{kV}, 20 \mathrm{~cm} \text { distance, } 5 \mathrm{~mL} / \mathrm{h}) \\
\text { Ultimate tensile strength }(\mathrm{MPa})\end{array}$ & Smooth without beads & Zhao et al. (2017) \\
& 10 to 25 & Zhang et al. (2009, 2012, 2014, 2018); \\
Strain at break $(\%)$ & 14 to 16 & Kandas et al. (2018) \\
Porosity $(\%)$ & 85 & Zhao et al. (2017) \\
\hline
\end{tabular}


from pathogen infections, gas passage, water retention, and mechanical protection. Electrospun silk mats have a relatively good oxygen permeability (a property of electrospun wound dressings), that does not prevent the supply of oxygen to the skin, necessary to the healing (Chomachayi et al. 2016). This characteristic also prevents the proliferation of pathogenic anaerobic bacteria in the wound (Wharram et al. 2010). Then, the high water uptake of silk, conserved in mats (Mohammadzadehmoghadam and Dong 2019), provides a moist environment for the wound. Electrospun mats are thin: about $1 \mathrm{~mm}$ in thickness. As their nanometric structure is close to the physiological tissues of the human body (Martins et al. 2007), the diffusion of natural homeotic compounds such as growth factors for skin regeneration (cytokines, EGF (Schneider et al. 2009)) is effective. Thus, the body response towards the injury is not slowed down by a hermetic barrier, while being protected by the dressing (Zhao et al. 2017) and protected from infections (Schneider et al. 2009). Interestingly, fibers' alignment randomness in mats is sometimes an obstacle to the regrowth of the organic tissues; however, method improvements for electrospinning made it possible to direct the orientation of the thread as it spreads on the collector (Sukigara et al. 2004).

\section{Scaffolds for cell growth}

A major number of studies mention electrospun spider silk mats as supports for cellular growth in regenerative medicine. As a natural polymer, silk is thought to conserve its potential biocompatibility (Anton and Kremer 2016), and express properties that resemble natural tissues to some extends. In the case of cells, the growth depends on the binding on specific chemical domains, according to their hydrophobicity. Silk from certain silkworm's fibroin (like Antheraea mylitta) composition is rich in polar, acid and basic amino acids, which helps with the adhesion of the cells on the scaffolds (Mhuka et al. 2013; Melke et al. 2016). The structure and porosity of the mats, unlike films that are usually used for wound dressing, allow the cultivated fibroblasts to thrive (Minoura et al. 1995) on 150 to $700 \mathrm{~nm}$ diameter meshes (Leal-Egaña et al. 2011) with relatively good rates: cells have an adhesion and a proliferation reaching $90 \%$ of the control plates' potential. This is due to the important specific surface of these mats: the more complex the topography (Bauer et al. 2013), the more anchoring sites for fibroblasts' filopodia, and therefore the more proliferation (Leal-Egaña et al. 2011). Studies led on diverse materials used for cell growth also show that over a porosity of $70 \%$, the cellular proliferation is more efficient, hence the interest of electrospun silk (Zhao et al. 2017). Silkworm's silk also served has cell growth scaffolds in some work. Electrospun mats of Bombyx silk have been shown to have potential for proliferation and adhesion of osteoblasts, but still remained outdone by synthetic supports such as culture polystyrene (TCPS) (Meechaisue et al. 2007). In this same approach, work by $\mathrm{Ki}$ et al. suggested that the conception of a 3D Bombyx silk fibroin scaffold, shaped as a sphere of randomly organized electrospun fibers, was more efficient in terms of cell adhesion and proliferation, these parameters also affected by a higher porosity (94\%) (Ki et al. 2008; Park et al. 2010).

\section{Tissue engineering}

The peculiar versatility of spider silk is used in several experiments as a strong and elastic prosthesis to replace fascia, in hernia repair. When compared with commercial synthetic homologues, the Nephila's silk woven mat has shown a remarkable integration in the organic tissues, with a lower inflammatory response, better durability of mechanical properties, and complete degradation observed after the healing of the wound (Schafer-Nolte et al. 2014). Even though applications with non-woven mats are not yet a reality, the biocompatibility results of spider silk is encouraging, while prospecting for potential non-woven meshes applications. Bombyx mori's silk, however, has already been used as an electrospun matrix to reconstruct damaged organic structures, such as blood vessels. Tubular scaffolds mimicking arteries with mechanical properties overtaking original models were successfully conceived by Soffer et al. (Soffer et al. 2008) and others (Steiner et al. 2019). With an ultimate tensile strength reaching up to $125 \%$ of an artery's potential and an average burst pressure of $811 \mathrm{mmHg}$, far over the biological standard of $100 \mathrm{mmHg}$ (Guyton 1991), these materials are very promising. Growth of endothelial and muscle cells have been observed to proliferate on the tubular scaffold. It makes it in an efficient support for grafts (Soffer et al. 2008). Bone tissues have also been grown on Bombyx fibroin electrospun mats, with a significantly higher proliferation of the osteoblasts on these scaffolds than on PLA synthetic homologues, which should contribute to the techniques of bone damage repairs and bone defect regeneration in future medical practices (Kim et al. 2005). These last years, Pawar et al. have been working on nerve guidance conduits made out of electrospun spider silk and collagen hybrid tubes. The peripheric tissues have shown excellent compatibility with cell growth and differentiation, the cells being able to achieve functional neuronal activity. Recombinant spider silk provided the anti-inflammatory barrier to the collagen compounds, while allowing the passage of nutrients and gas exchanges (Pawar et al. 2019; Salehi et al. 2020).

\section{Drug delivery}

Drug delivery is a complex process, as the efficiency of the drug depends on the accuracy of the targeted organic structure, and the diffusion rate of the medication. Recent 
advances in this domain have aimed to embed drug compounds in vector-like entities, based on the chemistry and kinetics of their degradation. Fibroin proteins have the capacity to retain a chemical compound and release it in the targeted organ at a controllable rate, which depends on its degree of crystallinity. The drug, sequestrated into the chains of the silk proteins, is only available for diffusion after their degradation. A higher crystallinity of the fiber implies a slower degradation by body enzymes, which releases the drugs embedded in the amorphous zones of the silk at a slower rate. Since the crystallization of silk fibers in electrospun mats can be largely controlled by vapor treatment, the delivery rate can therefore be defined (Pignatelli et al. 2018). Schneider et al. used a blend of silkworm's fibroin, PEO and EGF (epidermal growth factor) to design electrospun mats that release, when in contact with a wound, the healing compound at a controlled rate. After 6 days of contact, about $25 \%$ of the embedded EGF had been delivered from the fibers to the wound, very significantly accelerating its closure in comparison with control patients (Schneider et al. 2009). More recently, Pignatelli et al. achieved a similar success embedding hPL (human platelets lysate), a cocktail of growth factors which include EGF and cytokines in an electrospun fibroin matrix.

\section{Other applications}

\section{Air filtration and water depollution}

As a biopolymer with mechanical properties comparable with petrol-based materials to some extent, but with its organic and recyclable nature in addition, fibroin fibers employ in similar applications have been investigated. Engineering project led by Lang, Jokisch and Scheibel used electrospun fibers of recombinant A.diadematus fibroin to create an air filter device. The mat, composed of fibers of 80 to $120 \mathrm{~nm}$ of diameter, filtered particles of very small size, under the micrometric scale. The interest of electrospinning in this example is the regularity of the obtained mat: as the filter is composed of several layers of small-scaled meshes, the uniformity of the mat is high, and the risk of defects in the device is decreased (Lang et al. 2013; Jokisch et al. 2017). Another recent example of utilization of electrospun silkworm's fibroin is the insertion of $\mathrm{TiO}_{2}$ nanoparticles in the silk mat for pesticide degradation. Silk, unlike numerous artificial alternatives, does not eventually break down into toxic compounds like microplastics in water. It also ensures the durable entrapment of $\mathrm{TiO} 2$ nanoparticles in the scaffold to avoid their release in nature. The mats were electrospun and atomized with the titanium dioxide, and their capacity to photocatalyze a selection of pesticides when placed in polluted water was assessed. Tests showed a promising photooxidation of the pesticides, and a good durability of the mats' degradation rate in time, ensuring their reusability (Aznar-Cervantes et al. 2020). In this application, silk provides an adequate support for $\mathrm{TiO}_{2}$, as the presence of $\mathrm{TiO}_{2}$ in silk mats of films has also been observed to increase the crystallization of silk, tightening the meshes around the particles (Feng et al. 2010). Moreover, fibroin is compatible with the photoactivity of the compound, and safe for its potential contexts of utilization in depollution.

\section{Support scaffolds for polymers}

In some applications, electrospun silk scaffolds are used for their relative strength and elasticity, potentially conserved at the nanometric scale. Their implementation into composites constitutes the support structure for other polymers with different (and often complementary) properties. Lately, mixing (not necessarily electrospun) silk and carbon nanotubes has offered a variety of applications for e-textiles and sensors. Ye et al., for example, have proofed that such a composite yarn conserved the properties of silk, previously described and of carbon nanotubes. Fabrics made out of this material are sensitive to their environmental parameters, such as electrical conductivity, thermal variations, or mechanical forces (Ye et al. 2019). This trend and its applications were explored using electrospinning. Studies led by Ayutsede et al. (Ayutsede et al. 2006) suggest the combination of the extreme strength of carbon nanotubes and Bombyx mori's silk fibers through electrospinning, to increase the Young's modulus of the carbon nanostructure. In another work on the same type of silk, scaffolds of silk fibroin coated with polypyrrole, an organic polymer used for its electrical conductivity, showed the same conductivity as free-standing polypyrrole, for an enhanced strain at break and rupture strength, an opportunity for their use in regenerative medicine (Aznar-Cervantes et al. 2012). Unlike with spinning methods, these electrospun scaffolds benefit from a greater precision and uniformity in their design for applications at a lower and more delicate scale, like biomedicine.

\section{UV-related applications in textile}

As for drug delivery or particles embedment, electrospun silk scaffolds can be implemented with a variety of compounds. These compounds often possess a specific activity that is the core of the considered application, however, without the support of the fibroin fibers, this activity could not be displayed in certain environments or on long-term. This is the case in textiles, for example, some compounds with reactions of interest under UV light cannot be implemented in regular fabrics or their activity maintained; however, the function is preserved in electrospun silk mats. Among these applications, the embedment of $\mathrm{TiO}_{2}$ and $\mathrm{SiO}_{2}$ in textiles is well-known to protect the fibers from UV, and accelerate 
the photodegradation of staining compounds such as wine or coffee on fabrics (Kirstein 2013). A self-cleaning composite of electrospun silkworm's fibroin, polyvynil alcohol (PVA) and titanium dioxide has been designed by $\mathrm{Wu}$ et al. (2018). In another work, Pang et al. 2019 have successfully electrospun silkworm's fibroin and three different fluorescent dyes in three blends. Using rhodamine, acridine orange or fluorescent sodium solubilized in the fibroin dope, they created samples of silk with applications as strips or icons shining under UV lights, for implementation on textiles. Obtained fluorescent colors ranged from the dark red to the bright yellow-green, depending on the concentration and the type of dye (Pang et al. 2019). Kandas et al. pursued the same goal in 2018 and created a spider silk electrospun mat embedded with cerium oxide, metallic nanoparticles with fluorescent properties. After exposure under UV, the mat emitted a green light, and its electrical conductivity behavior changed depending on the humidity conditions and surrounding media, which grants the material potential applications in intelligent textiles (Kandas et al. 2018).

\section{Conclusion}

Silk, the ancient natural fiber, has conquered far more than the textile market. These last decades of research have revealed the secrets of its nature, displaying the unique structure of fibroin: a semi-crystalline long chain of amino acids, whose modular chemical bonds ensure both significant strength against rupture, and outstanding elasticity. The biomaterial, evolutionarily selected for these qualities, can withstand huge strain forces with remarkable resilience and be adapted to its contexts of use with a surprising versatility. Whereas silkworm silk is an acclaimed fiber for its biocompatibility, its availability and ease of manipulation, the most inspiring of silk is probably spider silk. Spidroin exhibits mechanical behavior that compete with high-performance material for its high strength, elasticity, biocompatibility, durability and low density: not so for its scores in these characteristics, but for the unique completeness of its profile. Moreover, this biopolymer is capable of behavior like no artificial fiber possesses, like supercontraction, and tailoring of properties using water. New applications even emerge to make use of silk's piezoelectricity and thermal properties. Numerous researches have worked with silks under their pristine or regenerated form, including electrospinning. The technique has the advantage of spinning mats with a nanometric scale: a chance to design scaffolds with specific topographies or compound embedment. Preparing an electrospinning dope out of fibroin is not always a simple process, for the obtention of the protein passes by the harvest and treatment of natural silk (a painstaking step for unfarmable spiders), or regeneration through genetically modified vectors. Spinning protocols however have been well defined in literature to create mats for a variety of applications. However, it is so far unclear whether the properties of natural silk have been fully retrieved in the final silk mats. Among their purposes, the biomedical applications rank as first. Electrospun fibroin mats have been effectively designed for cell growth, for their structure and the biocompatibility of silk provide the best culture environment. With similar outcomes, wound dressing has also experimented fibroin mats, the biological yet antibacterial nature of the silks complying with the human healing pathways. As a scaffold with nanoscopic pores that breaks down into harmless compounds at a well-understood rate, silk mats also make efficient carriers for drug delivery. A few other applications out of the medical domain exist, but they are rather remote. Electrospun mats have been used as support for more fragile polymers with value. The objective is to throw the properties of both into one composite. If the silk scaffold is necessary to the resilience of the overall nanoscopic device, its potential as a biopolymer is not fully exploited. It is safe to conclude that electrospinning silk, from silkworm or spider, is relevant for biomedical purposes, and so confirm the extending number of publications in that domain. Indeed, the scarcity of the material is compensated by the specific match between biomaterial's properties, spinning technique, and scale and context of application. However, for other applications, such as filtration, textile, or composites with various uses, electrospinning silk remains controversial. These frameworks can difficultly make use of more than one interest of our electrospun biomaterial's, because alternatives are ready and available, surpassing a biopolymer's limits, and the biomimetic feature with promises of recyclability and life-friendliness cannot offset this in the current market. Nevertheless, spinning and production techniques set aside, silk's potential remain significant for the right application. The polymer has an undeniable future in medical domains, and the growing visibility of both this material and electrospinning technique should certainly inspire numerous projects in the years to come.

\section{References}

Agarwal S, Wendorff JH, Greiner A (2008) Use of electrospinning technique for biomedical applications. Polymer (Guildf) 49:5603-5621. https://doi.org/10.1016/j.polymer.2008.09.014

Agnarsson I, Boutry C, Wong S-CC et al (2009) Supercontraction forces in spider dragline silk depend on hydration rate. Zool 112:325-331. https://doi.org/10.1016/j.zool.2008.11.003

Aguilar MR, San Román J (2019) Smart polymers and their applications. Woodhead Publishing, Cambridge

Akiyama M, Morofuji Y, Kamohara T et al (2006) Flexible piezoelectric pressure sensors using oriented aluminum nitride thin films prepared on polyethylene terephthalate films. J Appl Phys 100:114318. https://doi.org/10.1063/1.2401312 
Altman GH, Diaz F, Jakuba C et al (2003) Silk-based biomaterials. Biomaterials 24:401-416. https://doi.org/10.1016/s0142 -9612(02)00353-8

Amiraliyan N, Nouri M, Kish MH (2010) Structural characterization and mechanical properties of electrospun silk fibroin nanofiber mats. Polym Sci Ser A 52:407-412. https://doi.org/10.1134/ S0965545x10040097

Andersen SO (1970) Amino acid composition of spider silks. Comp Biochem Physiol 35:705-711. https://doi.org/10.1016/0010406x(70)90988-6

Anton AM, Kremer F (2016) Spider silk and its application in technology and medicine. In: Equipment. https://analyticalscience.wiley. com/do/https://doi.org/10.1002/gitlab.15278/full/. Accessed 14 Nov 2020

Asrar J, Hill JC (2002) Biosynthetic processes for linear polymers. J Appl Polym Sci 83:457-483. https://doi.org/10.1002/app.2253

Ayoub NA, Garb JE, Tinghitella RM et al (2007) Blueprint for a highperformance biomaterial: full-length spider dragline silk genes. PLoS ONE 2:e514. https://doi.org/10.1371/journal.pone.00005 14

Ayutsede J, Gandhi M, Sukigara S et al (2005) Regeneration of Bombyx mori silk by electrospinning. Part 3: characterization of electrospun nonwoven mat. Polymer (Guildf) 46:1625-1634. https:// doi.org/10.1016/j.polymer.2004.11.029

Ayutsede J, Gandhi M, Sukigara S et al (2006) Carbon nanotube reinforced Bombyx mori silk nanofibers by the electrospinning process. Biomacromol 7:208-214. https://doi.org/10.1021/bm050 5888

Aznar-Cervantes S, Roca MI, Martinez JG et al (2012) Fabrication of conductive electrospun silk fibroin scaffolds by coating with polypyrrole for biomedical applications. Bioelectrochemistry 85:36-43. https://doi.org/10.1016/j.bioelechem.2011.11.008

Aznar-Cervantes S, Aliste M, Garrido I et al (2020) Electrospun silk fibroin/TiO2 mats. Preparation, characterization and efficiency for the photocatalytic solar treatment of pesticide polluted water. RSC Adv 10:1917-1924. https://doi.org/10.1039/c9ra09239k

Babu KM (2018) Silk: processing, properties and applications. Woodhead Publishing, Cambridge

Basu A (2015) Advances in silk science and technology. Woodhead Publishing, Cambridge

Bauer F, Wohlrab S, Scheibel T (2013) Controllable cell adhesion, growth and orientation on layered silk protein films. Biomater Sci 1:1244-1249. https://doi.org/10.1039/c3bm60114e

Bell FI, McEwen IJ, Viney C (2002) Supercontraction stress in wet spider dragline. Nature 416:37. https://doi.org/10.1038/416037a

Benyus JM (1997) Biomimicry: innovation inspired by nature. Harper Perennia, New York

Bhattacharyya D, Maitrot P, Fakirov S (2009) Polyamide 6 single polymer composites. Express Polym Lett 3:525-532. https://doi. org/10.3144/expresspolymlett.2009.65

Blackledge TA, Boutry C, Wong S-C et al (2009) How super is supercontraction? Persistent versus cyclic responses to humidity in spider dragline silk. J Exp Biol 212:1981-1989. https://doi. org/10.1242/jeb.028944

Blackledge TA, Pérez-Rigueiro J, Plaza GR et al (2012) Sequential origin in the high performance properties of orb spider dragline silk. Sci Rep 2:782. https://doi.org/10.1038/srep00782

Blamires SJ, Sellers WI (2019) Modelling temperature and humidity effects on web performance: implications for predicting orb-web spider (Argiope spp.) foraging under Australian climate change scenarios. Conserv Physiol 7:coz083. https://doi.org/10.1093/ conphys/coz083

Bognitzki M, Czado W, Frese T et al (2001) Nanostructured fibers via electrospinning. Adv Mater 13:70-72. https://doi. org/10.1002/1521-4095(200101)13:1\%3c70::Aid-Adma7 0\%3e3.3.Co;2-8
Bonino MJ (2003) Material properties of spider silk. University of Rochester, Rochester, NY

Boutry C, Blackledge TA (2010) Evolution of supercontraction in spider silk: structure-function relationship from tarantulas to orbweavers. J Exp Biol 213:3505-3514. https://doi.org/10.1242/ jeb.046110

Boutry C, Blackledge TA (2013) Wet webs work better: humidity, supercontraction and the performance of spider orb webs. J Exp Biol 216:3606-3610. https://doi.org/10.1242/jeb.084236

Cao J, Akkerman R, Boisse P et al (2008) Characterization of mechanical behavior of woven fabrics: Experimental methods and benchmark results. Compos Part a Appl Sci Manuf 39:1037-1053. https://doi.org/10.1016/j.compositesa.2008.02.016

Casas J (2011) Spider physiology and behaviour: behaviour. Academic Press, Cambridge

Chakravorty R, Dutta P, Ghose J (2010) Sericulture and traditional craft of silk weaving in Assam. Indian J Tradit Knowl 9:378-385

Chen X, Shao Z, Vollrath F (2006) The spinning processes for spider silk. Soft Matter 2:448-451. https://doi.org/10.1039/b601286h

Chen F, Porter D, Vollrath F (2012) Silk cocoon (Bombyx mori): multi-layer structure and mechanical properties. Acta Biomater 8:2620-2627. https://doi.org/10.1016/j.actbio.2012.03.043

Chomachayi MD, Solouk A, Mirzadeh H (2016) Electrospun silk-based nanofibrous scaffolds: fiber diameter and oxygen transfer. Prog Biomater 5:71-80. https://doi.org/10.1007/s40204-016-0046-6

Chung H, Kim TY, Lee SY (2012) Recent advances in production of recombinant spider silk proteins. Curr Opin Biotechnol 23:957964. https://doi.org/10.1016/j.copbio.2012.03.013

Clements LL (1998) Organic fibers. In: Peters ST (ed) Handbook of Composites. Springer, Berlin, pp 202-241

Collins PG, Avouris P (2000) Nanotubes for electronics. Sci Am 283:62-69. https://doi.org/10.1038/scientificamerican1200-62

Craig CL (1997) Evolution of arthropod silks. Annu Rev Entomol 42:231-267. https://doi.org/10.1146/annurev.ento.42.1.231

Craig CL, Brunetta L (2010) Spider silk: evolution and 400 million years of spinning, waiting, snagging, and mating. Yale University Press, London

Craig CL, Riekel C (2002) Comparative architecture of silks, fibrous proteins and their encoding genes in insects and spiders. Comp Biochem Physiol Part B Biochem Mol Biol 133:493-507

Cunniff PM, Fossey SA, Auerbach MA et al (1994) Mechanical and thermal properties of dragline silk from the spider Nephila clavipes. Polym Adv Technol 5:401-410. https://doi.org/10.1002/ pat.1994.220050801

Das S, Bhowmick M, Chattopadhyay SK, Basak S (2015) Application of biomimicry in textiles. Curr Sci 109:893-901. https:// doi.org/10.18520/v109/i5/893-901

Dayyoub T, Maksimkin AV, Kaloshkin S et al (2019) The structure and mechanical properties of the uhmwpe films modified by the mixture of graphene nanoplates with polyaniline. Polymers (Basel) 11:23. https://doi.org/10.3390/polym11010023

De Araújo M (2011) Natural and man-made fibres: physical and mechanical properties. In: Fangueiro R (ed) Fibrous and composite materials for civil engineering applications. Elsevier, Amsterdam, pp 3-28. https://doi.org/10.1533/9780857095583.1.3

Desai M, Di R, Fan H (2019) Application of Biolayer Interferometry for Studying Protein-Protein Interactions in Transcription. J Vis Exp. https://doi.org/10.3791/59687

DeSimone E, Aigner TB, Humenik M et al (2020) Aqueous electrospinning of recombinant spider silk proteins. Mater Sci Eng C Mater Biol Appl 106:110145. https://doi.org/10.1016/j. msec.2019.110145

Dionne J, Lefèvre T, Bilodeau P et al (2017) A quantitative analysis of the supercontraction-induced molecular disorientation of major ampullate spider silk. Phys Chem Chem Phys 19:31487-31498. https://doi.org/10.1039/C7CP05739C 
Doblhofer E, Heidebrecht A, Scheibel T (2015) To spin or not to spin: spider silk fibers and more. Appl Microbiol Biotechnol 99:93619380. https://doi.org/10.1007/s00253-015-6948-8

Du N, Yang Z, Liu XY et al (2011) Structural Origin of the StrainHardening of Spider Silk. Adv Funct Mater 21:772-778. https:// doi.org/10.1002/adfm.201001397

Eisoldt L, Smith A, Scheibel T (2011) Decoding the secrets of spider silk. Mater Today 14:80-86. https://doi.org/10.1016/S1369 -7021(11)70057-8

Elices M, Plaza GR, Pérez-Rigueiro J et al (2011) The hidden link between supercontraction and mechanical behavior of spider silks. J Mech Behav Biomed Mater 4:658-669. https://doi. org/10.1016/j.jmbbm.2010.09.008

Emile O, Le Floch A, Vollrath F (2006) Biopolymers: shape memory in spider draglines. Nature 440:621. https://doi.org/10.1038/44062 1a

Feng XX, Zhou L, Zhu HL, Chen JY (2010) Study on the properties of Nano-TiO2 particles modified silk fibroin porous films. J Appl Polym Sci 116:468-472. https://doi.org/10.1002/app.31527

Fukada E (1956) On the piezoelectric effect of silk fibers. J Phys Soc Japan 11:1301A-1301A. https://doi.org/10.1143/JPSJ.11.1301A

Garb JE, Ayoub NA, Hayashi CY (2010) Untangling spider silk evolution with spidroin terminal domains. BMC Evol Biol 10:243. https://doi.org/10.1186/1471-2148-10-243

Gellynck K, Verdonk P, Forsyth R et al (2008) Biocompatibility and biodegradability of spider egg sac silk. J Mater Sci Mater Med 19:2963-2970. https://doi.org/10.1007/s10856-007-3330-0

Gorrasi G, Sorrentino A, Lichtfouse E (2020) Back to plastic pollution in COVID times. Environ Chem Lett. https://doi.org/10.1007/ s10311-020-01129-Z

Guinea GV, Elices M, Perez-Rigueiro J et al (2005) Stretching of supercontracted fibers: a link between spinning and the variability of spider silk. J Exp Biol 208:25-30. https://doi.org/10.1242/ jeb.01344

Gulrajani ML (1992) Degumming of silk. Rev Prog Color Relat Top 22:79-89. https://doi.org/10.1111/j.1478-4408.1992.tb00091.x

Guo Y, Shen Y-HH, Sun W et al (2011) Nucleotide diversity and selection signature in the domesticated silkworm, Bombyx mori, and wild silkworm. Bombyx mandarina J Insect Sci 11:155. https:// doi.org/10.1673/031.011.15501

Guyton AC (1991) Blood pressure control-special role of the kidneys and body fluids. Science (80-) 252:1813-1816. https://doi. org/10.1126/science.2063193

Hao W, Zhang X, Tian Y (2019) Thermal, mechanical, and microstructural study of PBO fiber during carbonization. Mater 12:608. https://doi.org/10.3390/ma12040608

He J-HH, Liu Y, Xu L et al (2008) BioMimic fabrication of electrospun nanofibers with high-throughput. Chaos Solitons Fractals 37:643-651. https://doi.org/10.1016/j.chaos.2007.11.028

Heim M, Keerl D, Scheibel T (2009) Spider silk: from soluble protein to extraordinary fiber. Angew Chem Int Ed Engl 48:3584-3596. https://doi.org/10.1002/anie.200803341

Herbort AF, Sturm MT, Fiedler S et al (2018) Alkoxy-silyl induced agglomeration: a new approach for the sustainable removal of microplastic from aquatic systems. J Polym Environ 26:42584270. https://doi.org/10.1007/s10924-018-1287-3

Holland C, Vollrath F, Ryan AJ, Mykhaylyk OO (2012) Silk and synthetic polymers: reconciling 100 degrees of separation. Adv Mater 24(104):105-109. https://doi.org/10.1002/adma.20110 3664

Holland C, Numata K, Rnjak-Kovacina J, Seib FP (2019) The biomedical use of silk: past, present Future. Adv Healthc Mater 8:1800465. https://doi.org/10.1002/adhm.201800465

Huang WM, Ding Z, Wang CC et al (2010) Shape memory materials. Mater Today 13:54-61. https://doi.org/10.1016/S1369 $-7021(10) 70128-0$
Huang X, Liu G, Wang X (2012) New secrets of spider silk: exceptionally high thermal conductivity and its abnormal change under stretching. Adv Mater 24:1482-1486. https://doi. org/10.1002/adma.201104668

Huang WW, Ling SJ, Li CM et al (2018) Silkworm silk-based materials and devices generated using bio-nanotechnology. Chem Soc Rev 47:6486-6504. https://doi.org/10.1039/c8cs00187a

Inouye K, Kurokawa M, Nishikawa S, Tsukada M (1998) Use of Bombyx mori silk fibroin as a substratum for cultivation of animal cells. J Biochem Biophys Methods 37:159-164. https ://doi.org/10.1016/S0165-022x(98)00024-4

Jamaluddin NA, Sheikh S, Hanan UA, et al (2019) Comparison of tensile properties between natural fibres and inorganic fibres for strengthening timber structures. In: MATEC web of conferences. p 1010

Jin H-JJ, Chen J, Karageorgiou V et al (2004) Human bone marrow stromal cell responses on electrospun silk fibroin mats. Biomaterials 25:1039-1047. https://doi.org/10.1016/s0142 -9612(03)00609-4

Jirsak O, Sanetrnik F, Lukas D et al (2009) Method of nanofibres production from a polymer solution using electrostatic spinning and a device for carrying out the method. U.S. Patent and Trademark Office, Washington

Jokisch S, Neuenfeldt M, Scheibel T (2017) Silk-based fine dust filters for air filtration. Adv Sustain Syst 1:1700079. https:// doi.org/10.1002/adsu.201700079

Kandas I, Shehata N, Hassounah I et al (2018) Optical fluorescent spider silk electrospun nanofibers with embedded cerium oxide nanoparticles. J Nanophotonics 12:26016. https://doi. org/10.1117/1.Jnp.12.026016

Karan SK, Maiti S, Kwon O et al (2018) Nature driven spider silk as high energy conversion efficient bio-piezoelectric nanogenerator. Nano Energy 49:655-666. https://doi.org/10.1016/j.nanoe n.2018.05.014

Karthik T, Rathinamoorthy R (2017) Sustainable silk production. In: Muthu SS (ed) Sustainable fibres and textiles. Elsevier, Amsterdam, pp 135-170

Ki CS, Park SY, Kim HJ et al (2008) Development of 3-D nanofibrous fibroin scaffold with high porosity by electrospinning: implications for bone regeneration. Biotechnol Lett 30:405410. https://doi.org/10.1007/s10529-007-9581-5

Kim K-HH, Jeong L, Park H-NN et al (2005) Biological efficacy of silk fibroin nanofiber membranes for guided bone regeneration. J Biotechnol 120:327-339. https://doi.org/10.1016/j.jbiot ec.2005.06.033

King JA, Tucker KW, Vogt BD et al (2004) Electrically and thermally conductive nylon 6,6. Polym Compos 20:643-654. https ://doi.org/10.1002/pc.10387

Kirchhoff MM (2003) Promoting green engineering through green chemistry. Env Sci Technol 37:5349-5353. https://doi. org/10.1021/es0346072

Kirstein T (2013) Multidisciplinary know-how for smart-textiles developers. Elsevier, Amsterdam

Knapczyk-Korczak J, Ura DP, Gajek M et al (2020) Fiber-based composite meshes with controlled mechanical and wetting properties for water harvesting. ACS Appl Mater Interfaces 12:1665-1676. https://doi.org/10.1021/acsami.9b19839

Krishna C, Pillai S, Sharma CP (2010) Absorbable polymeric surgical sutures: chemistry production, properties, biodegradability, and performance. J Biomater Appl. https://doi. org/10.1177/0885328210384890

Kuhbier JW, Reimers K, Kasper C et al (2011) First investigation of spider silk as a braided microsurgical suture. J Biomed Mater Res Part B Appl Biomater 97:381-387. https://doi. org/10.1002/jbm.b.31825 
Kumar B, Singh KP (2014) Fatigueless response of spider draglines in cyclic torsion facilitated by reversible molecular deformation. Appl Phys Lett 105:213704. https://doi. org/10.1063/1.4902942

Kumar S, Dang TD, Arnold FE et al (2002) Synthesis, structure, and properties of $\mathrm{PBO} / \mathrm{SWNT}$ composites \& Macromolecules 35:9039-9043. https://doi.org/10.1021/ma0205055

Kumar B, Thakur A, Panda B, Singh KP (2014) Optically probing torsional superelasticity in spider silks. Appl Phys Lett 103:201910. https://doi.org/10.1063/1.4831766. https://aip.scitation.org/ doi/10.1063/1.4902942

Kumar R, Priyanka M, Kartikey M, Aniruddha V (2018) Electrospinning production of nanofibrous membranes. Environ Chem Lett. https://doi.org/10.1007/s10311-018-00838-w

Kumar S, Zindani D, Bhowmik S (2020) Investigation of mechanical and viscoelastic properties of flax- and ramie-reinforced green composites for orthopedic implants. J Mater Eng Perform. https ://doi.org/10.1007/s11665-020-04845-3

Laity PR, Gilks SE, Holland C (2015) Rheological behaviour of native silk feedstocks. Polymer (Guildf) 67:28-39. https://doi. org/10.1016/j.polymer.2015.04.049

Lang G, Jokisch S, Scheibel T (2013) Air filter devices including nonwoven meshes of electrospun recombinant spider silk proteins. J Vis Exp. https://doi.org/10.3791/50492

Lauterbach AY, Scheibel T (2015) Life cycle assessment of spider silk nonwoven meshes in an air filtration device. Green Mater 3:15-24. https://doi.org/10.1680/gmat.14.00011

Leach MK, Feng Z-QQ, Tuck SJ, Corey JM (2011) Electrospinning fundamentals: optimizing solution and apparatus parameters. J Vis Exp. https://doi.org/10.3791/2494

Leal-Egaña A, Lang G, Mauerer C et al (2011) Interactions of fibroblasts with different morphologies made of an engineered spider silk protein. Adv Eng Mater 14:B67-B75. https://doi. org/10.1002/adem.201180072

Lerman MJ, Lembong J, Muramoto S et al (2018) The evolution of polystyrene as a cell culture material. Tissue Eng Part B Rev 24:359-372. https://doi.org/10.1089/ten.TEB.2018.0056

Li X-G, Huang M-R (1999) Thermal degradation of Kevlar fiber by high-resolution thermogravimetry. J Appl Polym Sci 71:565-571. https://doi.org/10.1002/(SICI)1097-4628(19990124)71:4\%3c565 ::AID-APP7\%3e3.0.CO;2-PCitation

Li D, Xia Y (2004) Electrospinning of nanofibers: reinventing the wheel? Adv Mater 16:1151-1170. https://doi.org/10.1002/ adma.200400719

Li M, Ogiso M, Minoura N (2003) Enzymatic degradation behavior of porous silk fibroin sheets. Biomaterials 24:357-365. https://doi. org/10.1016/s0142-9612(02)00326-5

Lin J, Wang X, Ding B et al (2012) Biomimicry via Electrospinning. Crit Rev Solid State Mater Sci 37:94-114. https://doi. org/10.1080/10408436.2011.627096

Liu X, Zhang K-Q (2014) Silk fiber-molecular formation mechanism, structure-property relationship and advanced applications. Oligomerization Chem Biol Compd. https://doi.org/10.5772/57611

Liu D, Yu L, He Y et al (2017) Peculiar torsion dynamical response of spider dragline silk. Appl Phys Lett 111:13701. https://doi. org/10.1063/1.4990676

Lu Q, Zhang B, Li M et al (2011) Degradation mechanism and control of silk fibroin. Biomacromol 12:1080-1086. https://doi. org/10.1021/bm101422j

Mandal BB, Kundu SC (2008) A novel method for dissolution and stabilization of non-mulberry silk gland protein fibroin using anionic surfactant sodium dodecyl sulfate. Biotechnol Bioeng 99:1482-1489. https://doi.org/10.1002/bit.21699

Martins A, Araújo JV, Reis RL et al (2007) Electrospun nanostructured scaffolds for tissue engineering applications. Nanomedicine (Lond) 2:929-942. https://doi.org/10.2217/17435889.2.6.929
Meechaisue C, Wutticharoenmongkol P, Waraput R et al (2007) Preparation of electrospun silk fibroin fiber mats as bone scaffolds: a preliminary study. Biomed Mater 2:181-188. https://doi. org/10.1088/1748-6041/2/3/003

Meinel AJ, Kubow KE, Klotzsch E et al (2009) Optimization strategies for electrospun silk fibroin tissue engineering scaffolds. Biomaterials 30:3058-3067. https://doi.org/10.1016/j.biomateria 1s.2009.01.054

Melke J, Midha S, Ghosh S et al (2016) Silk fibroin as biomaterial for bone tissue engineering. Acta Biomater 31:1-16. https://doi. org/10.1016/j.actbio.2015.09.005

Merrit JL et al. (1992) Silk: history, cultivation, and processing. In: Silk: Harper's Ferry Regional Textile Group, 11th Symposium, 12-13 November 1992, National Museum of American History

Mhuka V, Dube S, Nindi MM (2013) Chemical, structural and thermal properties of Gonometa postica silk fibroin, a potential biomaterial. Int J Biol Macromol 52:305-311. https://doi.org/10.1016/j. ijbiomac.2012.09.010

Min B-MM, Lee G, Kim SH et al (2004) Electrospinning of silk fibroin nanofibers and its effect on the adhesion and spreading of normal human keratinocytes and fibroblasts in vitro. Biomaterials 25:1289-1297. https://doi.org/10.1016/j.biomateria 1s.2003.08.045

Minoura N, Aiba S-I, Higuchi M et al (1995) Attachment and growth of fibroblast cells on silk fibroin. Biochem Biophys Res Commun 208:511-516. https://doi.org/10.1006/bbrc.1995.1368

Mitchell GR, Tojeira A (2013) Role of Anisotropy in Tissue Engineering. Procedia Eng 59:117-125. https://doi.org/10.1016/j.proen g.2013.05.100

Mohammadzadehmoghadam S, Dong Y (2019) Fabrication and Characterization of Electrospun Silk Fibroin/Gelatin Scaffolds Crosslinked With Glutaraldehyde Vapor. Front Mater 6:1-12. https://doi.org/10.3389/fmats.2019.00091

Monteiro SN, Satyanarayana KG, Lopes FPD (2010) High strength natural fibers for improved polymer matrix composites. Materials Science Forum. Trans Tech Publications, Switzerland, pp 961-966. http://www.scientific.net/MSF.638-642.961

Müller-Herrmann S, Scheibel T (2015) Enzymatic degradation of films, particles, and nonwoven meshes made of a recombinant spider silk protein. ACS Biomater Sci Eng 1:247-259. https:// doi.org/10.1021/ab500147u

Nentwig W (2012) Ecophysiology of spiders. Springer Science \& Business Media, Berlin

Neukirch et al (2020) La mécanique des toiles d'araignées

Neukirch S, Antkowiak A, Rollard C, Vollrath F (2017) Le treuil élastocapillaire dans les toiles d'araignées

Nova A, Keten S, Pugno NM et al (2010) Molecular and nanostructural mechanisms of deformation, strength and toughness of spider silk fibrils. Nano Lett 10:2626-2634. https://doi.org/10.1021/ nl101341w

Numata K, Kaplan DL (2010) Silk-based delivery systems of bioactive molecules. Adv Drug Deliv Rev 62:1497-1508. https://doi. org/10.1016/j.addr.2010.03.009

Nune SK, Rama KS, Dirisala VR, Chavali MY (2017) Electrospinning of collagen nanofiber scaffolds for tissue repair and regeneration. In: Ficai D, Grumezescu AM (eds) Nanostructures for novel therapy. Elsevier, pp 281-311. https://www.sciencedir ect.com/book/9780323461429/nanostructures-for-novelthera py\#: :text=Molecular\%20nanostructures\%20with\%20wel $1 \%$ 2Ddefined,biomedical\%20applications\%20than $\% 20$ linear $\% 20$ polymers

Ogawa T, Mukai H, Osawa S (1998) Mechanical properties of ultrahigh-molecular-weight polyethylene fiber-reinforced PE composites. J Appl Polym Sci 68:1431-1439. https:// doi.org/10.1002/(sici)1097-4628(19980531)68:9\%3c143 $1:$ Aid-app7\%3e3.0.Co;2-c 
Ohgo K, Zhao C, Kobayashi M, Asakura T (2003) Preparation of nonwoven nanofibers of Bombyx mori silk, Samia cynthia ricini silk and recombinant hybrid silk with electrospinning method. Polymer (Guildf) 44:841-846. https://doi.org/10.1016/s0032 -3861(02)00819-4

Opell BD, Lipkey GK, Hendricks ML, Vito ST (2009) Daily and seasonal changes in the stickiness of viscous capture threads in Argiope aurantia and Argiope trifasciata orb-webs. J Exp Zool A Ecol Genet Physiol 311:217-225. https://doi.org/10.1002/jez.526

Padervand M, Lichtfouse E, Robert D, Wang C (2020) Removal of microplastics from the environment. A Rev Environ Chem Lett 18:807-828. https://doi.org/10.1007/s10311-020-00983-1

Pang L, Ming J, Pan F, Ning X (2019) Fabrication of silk fibroin fluorescent nanofibers via electrospinning. Polym 11:986. https://doi. org/10.3390/polym11060986

Park SY, Ki CS, Park YH et al (2010) Electrospun silk fibroin scaffolds with macropores for bone regeneration: an in vitro and in vivo study. Tissue Eng Part A 16:1271-1279. https://doi.org/10.1089/ ten.TEA.2009.0328

Pawar K, Welzel G, Haynl C et al (2019) Recombinant spider silk and collagen-based nerve guidance conduits support neuronal cell differentiation and functionality in vitro. ACS Appl Bio Mater 2:4872-4880. https://doi.org/10.1021/acsabm.9b00628

Peng Q, Zhang Y, Lu L et al (2016) Recombinant spider silk from aqueous solutions via a bio-inspired microfluidic chip. Sci Rep 6:36473. https://doi.org/10.1038/srep36473

Pereira RFP, Silva MM, de Zea BV (2015) Bombyx mori silk fibers: an outstanding family of materials. Macromol Mater Eng 300:1171-1198

Pérez-Rigueiro J, Viney C, Llorca J, Elices M (2000) Mechanical properties of single-brin silkworm silk. J Appl Polym Sci 75:1270-1277. https://doi.org/10.1002/(sici)1097-4628(20000 307)75:10\%3c1270::Aid-app8\%3e3.0.Co;2-c

Pignatelli C, Perotto G, Nardini M et al (2018) Electrospun silk fibroin fibers for storage and controlled release of human platelet lysate. Acta Biomater 73:365-376. https://doi.org/10.1016/j.actbi o.2018.04.025

Quintanilla J (1999) Microstructure and properties of random heterogeneous materials: A review of theoretical results. Polym Eng Sci 39:559-585. https://doi.org/10.1002/pen.11446

Raheel M (1994) Protective clothing; An Overview. In: Raheel M (ed) Protective clothing systems materials. Marcel Dekker Inc, New York, pp 1-23

Ramakrishna S (2005) An introduction to electrospinning and nanofibers. World Scientific, Singapore

Rangari VK, Yousuf M, Jeelani S et al (2008) Alignment of carbon nanotubes and reinforcing effects in nylon- 6 polymer composite fibers. Nanotechnology 19:245703. https://doi.org/10.1088/09574484/19/24/245703

Reap J, Baumeister D, Bras B (2005) Holism, biomimicry and sustainable engineering. ASME 2005 International Mechanical Engineering Congress and Exposition. Orlando, Florida, pp 423-431

Romer L, Scheibel T, Römer L, Scheibel T (2008) The elaborate structure of spider silk: structure and function of a natural high performance fiber. Prion 2:154-161. https://doi.org/10.4161/ pri.2.4.7490

Sahni V, Blackledge TA, Dhinojwala A (2011) Changes in the adhesive properties of spider aggregate glue during the evolution of cobwebs. Sci Rep 1:41. https://doi.org/10.1038/srep00041

Salehi S, Koeck K, Scheibel T (2020) Spider silk for tissue engineering applications. Molecules 25:737. https://doi.org/10.3390/molec ules25030737

Sappati KK, Bhadra S (2018) Piezoelectric polymer and paper substrates: a review. Sensors (Basel) 18:3605. https://doi. org/10.3390/s18113605
Sasithorn N, Martinová L (2014) Fabrication of silk nanofibres with needle and roller electrospinning methods. J Nanomater 2014:19. https://doi.org/10.1155/2014/947315

Schafer-Nolte F, Hennecke K, Reimers K et al (2014) Biomechanics and biocompatibility of woven spider silk meshes during remodeling in a rodent fascia replacement model. Ann Surg 259:781792. https://doi.org/10.1097/SLA.0b013e3182917677

Schneider A, Wang XY, Kaplan DL et al (2009) Biofunctionalized electrospun silk mats as a topical bioactive dressing for accelerated wound healing. Acta Biomater 5:2570-2578. https://doi. org/10.1016/j.actbio.2008.12.013

Seely L, Zimmerman M, McLaughlin J (2004) The use of Zylon fibers in ULDB tendons. Adv Sp Res 33:1736-1740. https://doi. org/10.1016/j.asr.2003.07.046. https://www.sciencedirect.com/ science/article/abs/pii/S0273117703011542?via\%3Dihub

Senthilkumar M, Anbumani N, Hayavadana J (2011) Elastane fabricsa tool for stretch applications in sports. Indian J Fibre Text Res 36:300-307

Shao Z, Vollrath F (2002) Surprising strength of silkworm silk. Nature 418:741. https://doi.org/10.1038/418741a

Shear WA, Palmer JM, Coddington JA, Bonamo PM (1989) A devonian spinneret: early evidence of spiders and silk use. Science 246:479-481. https://doi.org/10.1126/science.246.4929.479

Shehata N, Hassounah I, Sobolciak P, et al (2019) Spider silk fibers: synthesis, characterization, and related biomedical applications. In: Grumezescu V, Grumezescu AM (eds) Materials for biomedical engineering. Elsevier, pp 289-307. https://www.sciencedir ect.com/book/9780128168721/materialsfor-biomedical-engin eering

Sheu H-SS, Phyu KW, Jean Y-CC et al (2004) Lattice deformation and thermal stability of crystals in spider silk. Int J Biol Macromol 34:325-331. https://doi.org/10.1016/j.ijbiomac.2004.09.004

Shi J, Yao D (2020) A simple process for making supercontraction fiber from polycaprolactone/elastomer blends. Polym Eng Sci 60:793-801. https://doi.org/10.1002/pen.25337

Shin S-HH, Purevdorj O, Castano O et al (2012) A short review: recent advances in electrospinning for bone tissue regeneration. J Tissue Eng 3:2041731412443530. https://doi.org/10.1177/20417 31412443530

Smith MJ, Flowers TH, Lennard FJ (2014) Mechanical properties of wool and cotton yarns used in twenty-first century tapestry: Preparing for the future by understanding the present. Stud Conserv 60:375-383. https://doi.org/10.1179/2047058414y.0000000144

Soffer L, Wang X, Zhang X et al (2008) Silk-based electrospun tubular scaffolds for tissue-engineered vascular grafts. J Biomater Sci Polym Ed 19:653-664. https://doi.org/10.1163/1568562087 84089607

Stankus JJ, Freytes DO, Badylak SF, Wagner WR (2008) Hybrid nanofibrous scaffolds from electrospinning of a synthetic biodegradable elastomer and urinary bladder matrix. J Biomater Sci Polym Ed 19:635-652. https://doi.org/10.1163/1568562087 84089599

Steiner D, Lang G, Fischer L et al (2019) Intrinsic vascularization of recombinant eADF4(C16) spider silk matrices in the arteriovenous loop model. Tissue Eng Part A 25:1504-1513. https:// doi.org/10.1089/ten.TEA.2018.0360

Steven E, Park JG, Paravastu A et al (2011) Physical characterization of functionalized spider silk: electronic and sensing properties. Sci Technol Adv Mater 12:55002. https://doi.org/10.1088/14686996/12/5/055002

Steven E, Saleh WR, Lebedev V et al (2013) Carbon nanotubes on a spider silk scaffold. Nat Commun 4:2435. https://doi. org/10.1038/ncomms 3435

Steven E, Lebedev V, Laukhina E et al (2014) Silk/nano-material hybrid: properties and functions. APS 2014:45-012 
Sukigara S, Gandhi M, Ayutsede J et al (2003) Regeneration of Bombyx mori silk by electrospinning — part 1: processing parameters and geometric properties. Polymer (Guildf) 44:5721-5727. https ://doi.org/10.1016/s0032-3861(03)00532-9

Sukigara S, Gandhi M, Ayutsede J et al (2004) Regeneration of Bombyx mori silk by electrospinning. Part 2. process optimization and empirical modeling using response surface methodology. Polymer (Guildf) 45:3701-3708. https://doi.org/10.1016/j.polym er.2004.03.059

Sun B, Liang D, Li X, Chen P (2015) Nonvolatile bio-memristor fabricated with natural bio-materials from spider silk. J Mater Sci Mater Electron 27:3957-3962. https://doi.org/10.1007/s1085 4-015-4248-9

Suzuki Y, Gage LP, Brown DD (1972) The genes for silk fibroin in Bombyx mori. J Mol Biol 70:637-649. https://doi. org/10.1016/0022-2836(72)90563-3

Swanson BO, Anderson SP, DiGiovine C et al (2009) The evolution of complex biomaterial performance: the case of spider silk. Integr Comp Biol 49:21-31. https://doi.org/10.1093/icb/icp013

Takai H, Ozawa R, Takabayashi J et al (2018) Silkworms suppress the release of green leaf volatiles by mulberry leaves with an enzyme from their spinnerets. Sci Rep 8:11942. https://doi.org/10.1038/ s41598-018-30328-6

Tanaka M, Moritaka Y (2004) Single bumper shields based on vectran fibers. Adv Sp Res 34:1076-1079. https://doi.org/10.1016/j. asr.2003.03.039

Tao W, Li M, Zhao C (2007) Structure and properties of regenerated Antheraea pernyi silk fibroin in aqueous solution. Int $\mathbf{J}$ Biol Macromol 40:472-478. https://doi.org/10.1016/j.ijbio mac.2006.11.006

Teule F, Addison B, Cooper AR et al (2012) Combining flagelliform and dragline spider silk motifs to produce tunable synthetic biopolymer fibers. Biopolymers 97:418-431. https://doi. org/10.1002/bip.21724

Thilagavathi G, Viju S (2015) Silk as a suture material. In: Basu A (ed) Advances in silk science and technology. Elsevier, pp 219-232. http://www.elsevier.com/books/advances-in-silk-science-andtechnology/basu/978-1-78242-311-9

Thompson AN, Hynd PI (2009) Stress-strain properties of individual Merino wool fibres are minor contributors to variations in staple strength induced by genetic selection and nutritional manipulation. Anim Prod Sci 49:668-674. https://doi.org/10.1071/ea082 03

Tokareva O, Jacobsen M, Buehler M et al (2014) Structure-function-property-design interplay in biopolymers: spider silk. Acta Biomater 10:1612-1626. https://doi.org/10.1016/j.actbi o.2013.08.020

Varadarajan G, Venkatachalam P (2016) Sustainable textile dyeing processes. Environ Chem Lett 14:113-122. https://doi.org/10.1007/ s10311-015-0533-3

Vendrely C, Scheibel T (2007) Biotechnological production of spidersilk proteins enables new applications. Macromol Biosci 7:401409. https://doi.org/10.1002/mabi.200600255

Vepari C, Kaplan DL (2007) Silk as a Biomaterial. Prog Polym Sci 32:991-1007. https://doi.org/10.1016/j.progpolyms ci.2007.05.013

Vierra C, Hsia Y, Gnesa E, et al (2011) Spider silk composites and applications. In: Cuppoletti J (ed) Metal, ceramic and polymeric composites for various uses. IntechOpen. https://www.intechopen .com/books/metal-ceramic-and-polymeric-composites-for-vario us-uses

Viney C (2009) From natural silks to new polymer fibres. J Text Inst 91:2-23. https://doi.org/10.1080/00405000008659539

Vollrath F, Edmonds DT (1989) Modulation of the mechanical properties of spider silk by coating with water. Nature 340:305-307. https://doi.org/10.1038/340305a0
Vollrath F, Knight DP (2001) Liquid crystalline spinning of spider silk. Nature 410:541-548. https://doi.org/10.1038/35069000

Vollrath F, Porter D (2006) Spider silk as archetypal protein elastomer. Soft Matter 2:377-385. https://doi.org/10.1039/b600098n

Wade LE (2015) Wound healing: cellular mechanisms alternative therapies and clinical outcomes. Nova Science Publishers, Incorporated, New York

Ward IM (2012) Structure and properties of oriented polymers. Springer Science \& Business Media, Berlin

Wharram SE, Zhang X, Kaplan DL, McCarthy SP (2010) Electrospun silk material systems for wound healing. Macromol Biosci 10:246-257. https://doi.org/10.1002/mabi.200900274

Work RW (1977) Dimensions, birefringences, and force-elongation behavior of major and minor ampullate silk fibers from orb-web-spinning spiders-the effects of wetting on these properties. Text Res J 47:650-662. https://doi. org/10.1177/004051757704701003. https://journals.sagep ub.com/doi/10.1177/004051757704701003

Wray LS, Hu X, Gallego J et al (2011) Effect of processing on silkbased biomaterials: reproducibility and biocompatibility. J Biomed Mater Res B Appl Biomater 99:89-101. https://doi. org/10.1002/jbm.b.31875

Wu M-C, Chan S-H, Lin T-H (2015) Fabrication and photocatalytic performance of electrospun PVA/silk/ $/ \mathrm{TiO}_{2}$ nanocomposite textile. Funct Mater Lett 08:1540013. https://doi.org/10.1142/ s1793604715400135

Wu Y, Shah DU, Wang B et al (2018) Biomimetic supramolecular fibers exhibit water-induced supercontraction. Adv Mater 30:e1707169. https://doi.org/10.1002/adma.201707169

Xu J, Dong Q, Yu Y et al (2018) Mass spider silk production through targeted gene replacement in Bombyx mori. Proc Natl Acad Sci U S A 115:8757-8762. https://doi.org/10.1073/pnas.18068 05115

Yan L, Kasal B, Huang L (2016) A review of recent research on the use of cellulosic fibres, their fibre fabric reinforced cementitious, geo-polymer and polymer composites in civil engineering. Compos Part B Eng 92:94-132. https://doi.org/10.1016/j.composites b.2016.02.002

Yang Y, Chen X, Shao Z et al (2005) Toughness of spider silk at high and low temperatures. Adv Mater 17:84-88. https://doi. org/10.1002/adma.200400344

Ye C, Ren J, Wang Y et al (2019) Design and fabrication of silk templated electronic yarns and applications in multifunctional textiles. Matter 1:1411-1425. https://doi.org/10.1016/j. matt.2019.07.016

Yi B, Zhang H, Yu Z et al (2018) Fabrication of high performance silk fibroin fibers via stable jet electrospinning for potential use in anisotropic tissue regeneration. J Mater Chem B 6:3934-3945. https://doi.org/10.1039/c8tb00535d

Yu H-SS, Shen Y-HH, Yuan G-XX et al (2011) Evidence of selection at melanin synthesis pathway loci during silkworm domestication. Mol Biol Evol 28:1785-1799. https://doi.org/10.1093/molbev/ msr002

Yucel T, Cebe P, Kaplan DL (2011) Structural origins of silk piezoelectricity. Adv Funct Mater 21:779-785. https://doi.org/10.1002/ adfm.201002077

Yükseloğlu SM, Çalişkan M, Çaliskan M (2015) Mechanical and thermal properties of wool waste fabric reinforced composites. Tekst ve Mühendis 22:14-20. https://doi.org/10.7216/13007 5992015229703

Zarkoob S, Eby RK, Reneker DH et al (2003) Structure and morphology of electrospun silk nanofibers. Polymer (Guildf) 45:39733977. https://doi.org/10.1016/j.polymer.2003.10.102

Zhang D, Chang J (2008) Electrospinning of three-dimensional nanofibrous tubes with controllable architectures. Nano Lett 8:32833287. https://doi.org/10.1021/n1801667s 
Zhang X, Reagan MR, Kaplan DL (2009) Electrospun silk biomaterial scaffolds for regenerative medicine. Adv Drug Deliv Rev 61:988-1006. https://doi.org/10.1016/j.addr.2009.07.005

Zhang F, Zuo B, Fan Z et al (2012) Mechanisms and control of silkbased electrospinning. Biomacromol 13:798-804. https://doi. org/10.1021/bm201719s

Zhang C, Zhang D, Chen D, Li MA (2014) Bilayered scaffold based on RGD recombinant spider silk proteins for small diameter tissue engineering. Polym Compos 37:523-531. https://doi. org/10.1002/pc.23208

Zhang Q-H, Dong J, Wu D-Z (2018) Advanced polyimide fibers. In: Yang S-Y (ed) Advanced polyimide materials. Elsevier, pp 67-92. https://www.sciencedirect.com/book/9780128126400/ advanced-polyimide-materials

Zhao H-P, Feng X-Q, Shi H-J (2006) Variability in mechanical properties of Bombyx mori silk. Mater Sci Eng C 27:675-683. https:// doi.org/10.1016/j.msec.2006.06.031

Zhao L, Chen D, Yao Q, Li M (2017) Studies on the use of recombinant spider silk protein/polyvinyl alcohol electrospinning membrane as wound dressing. Int J Nanomedicine 12:8103-8114. https:// doi.org/10.2147/IJN.S47256

Zhou S, Peng H, Yu X et al (2008) Preparation and characterization of a novel electrospun spider silk fibroin/poly(D, L-lactide) composite fiber. J Phys Chem B 112:11209-11216. https://doi. org/10.1021/jp800913k

Zhou J, Cao C, Ma X (2009) A novel three-dimensional tubular scaffold prepared from silk fibroin by electrospinning. Int J Biol Macromol 45:504-510. https://doi.org/10.1016/j.ijbiomac.2009.09.006

Zhu J, Zhu H, Njuguna J, Abhyankar H (2013) Recent development of flax fibres and their reinforced composites based on different polymeric matrices. Mater 6:5171-5198. https://doi.org/10.3390/ ma6115171

Publisher's Note Springer Nature remains neutral with regard to jurisdictional claims in published maps and institutional affiliations. 